(Aus dem physik. Institut der technischen Hochschule Aachen.)

\title{
Ueber \\ die Empfindlichkeit des menschlichen Ohres für Töne verschiedener Höhe.
}

Von

Max Wien.

(Mit 12 Textfiguren.)

In h a l t.

Finleitung.

I. Versuche, bei denen die Tonintensität am Ohre gemessen wurde (Telephonempfindlichkeit) ................... 5

II. Versuche, bei denen die Tonintensität an der Tonquelle gemessen wurde 20

III. Absolute Empfindlichkeit des Ohres . . . . . . . . . . . . 31

IV. Normale und kranke Ohren. . . . . . . . . . . . . 34

Anhang I: Berechnung der durch erzwungene Schwingungen einer Platte an einem entfernten Ort erzeugten Tonintensität . . . . . . . 41

Anhang II: Bemerkungen zu den Arbeiten der Merren $Z_{\text {waardemaker }}$

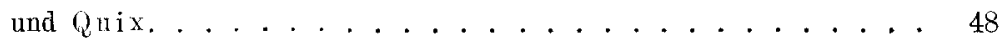

Es ist allgemein bekannt, dass unser Ohr, ebenso wio unser Auge, nur für einen bestimmten Bereich von Schwingungszahlen empfindlich ist. Sehr langsame Schallschwingungen und sehr schnelle hören wir gar nicht oder nur sehr unvollkommen.

Wie bängt nun innerhalb dieser Grenzen die Empfindlichkeit des Ohres von der Tonhöhe ab? Setzt sie plötzlich ein, bleibt dann innerhalb des Hörbereichs annähernd constant, um dann plötzlich wieder abzufallen - so würde es eigentlich die Helmholtz'sche Resonanztheorie verlangen - oder steigt sie langsam bis zu einem - vielleicht spitzen - Maximum an und fällt dann allmählich wieder $a b$ ? Sind innerhalb dieser Grenzen sehr grosse Unterschiede in der Empfindlichkeit? Hört man z. B. einen Ton von 2000 Schwingungen in der Secunde 10, 1000 oder eine Million Mal so gut wie einen Ton von 50 Schwingungen?

E. Pf́lüger, Archiv für Physiologie. Bd. 97. 
Beginnen wir zunächst mit der oberen und unteren Grenze der hörbaren Töne. Dass über diese Grenzen gestritten wird, dass man noch nicht einig darüber ist, ob die Hörbarkeit bei 10 oder bei 40 Schwingungen beginnt, beweist, dass keine scharfe Grenze vorhanden sein kann. Ebenso liegt es bei den hohen Tönen; bei denselben wurde früher eine Schwingungszahl von 20-30000 als Grenze angenommen. Noch im Jahre 1900 führte mir der Akustiker Rudolph König in Paris eine Reihe hoher Stimmgabeln vor, mit denen ich deutlich bei mir eine scharfe obere Grenze bei etwa 26000 Schwingungen feststellen zu können glaubte. Wenige Monate darauf äberzengte ich mich durch Versuche mit der neuen $\mathrm{Edelmann}$ 'schen Galtonpfeife, dass nicht nur ich, sonderu die meisten Menschen bis zu 45000 Schwingungen wahrzunehmen vermögen. Dies kann doch wohl nur so erklärt werden, dass die Stimmgabeltöne zu schwach waren, um bei der geringen Empfindlichkeit der Ohren für ganz hohe Töne noch eine Empfindung zu erregen. Die Empfindlichkeit nimmt mit der Höhe bei Tönen über 20000 Sehwingungen stark ab, aber die Hörbarkeit würde wohl noch viel weiter als 45000 gehen, wenn man nur die Intensität genügend steigern könnte. Sowohl bei den sehr tiefen wie bei den sehr hohen Tönen ist kein plötzlicher, sondern ein allmählicher Abfall der Empfindlichkeit vorhanden, der sich über mehrere Octaven hinzieht.

Während für das Auge die Empfindlichkeitscurve für den ganzen Bereich der sichtbaren Strahlen durch Ebert ${ }^{1}$ ), Langley ${ }^{2}$, $\mathrm{K} \ddot{o ̈ n i g^{3}}$ ), Pflü $\mathrm{ger}^{4}$ ) u. A. festgestellt ist, ist für das Ohr nur sehr wenig darüber bekannt, wie sich innerhalb der Hörgrenzen die Empfindlichkeit mit der Tonhöhe ändert. Wohl findet man häufig in der Literatur die Ansicht ausgesprochen, dass man hohe Töne besser vernähme als tiefe. So sagt z. B. Stumpfä): „Die Vergleichung gleichzeitiger Töne lehrt noch klarer als die auf einander folgender, dass die höheren Töne bei gleicher Reizstärke grössere Empfindungsstärke besitzen: Die winzige Pickelflöte übertönt in ihren höheren Lagen in der vier gestrichenen Octave bequem das gesammte Orchester, selbst das Blech. Ein einziger guter Sopran beherrscht

1) H. Ebert, Wiedemann's Annalen Bd. 33 S. 136.1888.

2) S. P. Langley, Phil. Mag. t. (5) 25 p. 1. 1889.

3) A. König, Beitr. z. Psych. u. Physiol. d. Sinnesorgane. Hamburg 1891.

4) A. Pflüger, Ann. d. Phys. Bd. 9 S. 185.1902.

5) Stumpf, Tonpsychologie Bd. 2 S. 417. Leipzig 1883. 
nicht minder Chor und Orchester, sobald seine Töne höher liegen. Weiss sich doch auch ein tüchtiges Canarienvögelchen gegen grossen Lärm geltend zu machen." Diese subjectiven Urtheile, denen keine Messung der physikalischen Intensität zur Seite steht, können wohl die grössere Empfindlichkeit des Ohres für höhere Töne plausibel machen, beweisen thun sie nichts. Einen experimentellen, allerdings nur qualitativen Beweis verdanken wir $\mathrm{Helmholtz}$. Derselbe sagt in seinen "Tonempfindungen" bei Gelegenheit der Beschreibung seiner Doppelsirene: „Wenn bei gleicher Energie des tonerzeugenden Luftstromes die Sirene immer schneller gedreht wird, so hat man anfangs, so lange die Sirene langsam läuft, einen schwachen tiefen Ton, der immer höher und höher wird, dabei aber gleichzeitig an Stärke ausserordentlich zunimmt, so dass die höchsten Töne von etwa 880 Schwingungen, die ich auf meiner Doppelsirene hervorbringe, eine kaum ertragbare Stärke haben. - Die Verluste durch Reibung müssen bei schneller Rotation grösser werden wie bei langsamer, so dass für die Hervorbringung der hohen 'Töne sogar weniger Arbeitskraft übrig bleibt als für die tiefen; und doch erscheinen in dor Empfindung die hohen Töne so ausserordentlich viel stärker als die tiefen Töne. Wie weit übrigens diese Steigerung nach der Höhe sich fortsetzt, kann ich bisher nicht angeben, weil die Geschwindigkeit meiner Sirene bei demselben Luftdruck eben nicht weiter gesteigert werden kann. - I)ie Zunahme der Tonstärke mit der Tonhöhe ist besonders bedeutend in der tiefsten Gegend der Scala." An die Möglichkeit, hierauf eine quantitative Bestimmung der Empfindlichkeit des Ohres für versehiedene Tonhöhen zu gründen, ist nicht zu denken, weil ein Urtheil über die relative Empfindungsstärke von Tönen verschiedener Höhe äusserst schwierig, wenn nicht unmöglich ist.

Ein anderes Mittel, um ein Maass für die Fmpfindlichkeit zu erhalten, wäre die Bestimmung der Unterschiedsschwelle für die Tonstärke $^{\mathbf{l}}$ ). Ich habe es versucht, jedoch bald wieder aufoegeben, da die Differenzen, welche sich für die versehiedenen Tonhöhen ergaben, viel zu klein sind, um darauf bei der Schwierigkeit der Beobachtung und der entsprechenden Grösse der Beobachtungsfehler eine Messung zu begründen.

Es bleibt nur die Methode der Reizschwelle, wobei die

1) Vgl. M. Wien, Ueber die Messung der Tonstärke. Dissert. Berlin 1888. Wiedemann's Ann. Bd. 36 S. 384. 1889. 
Energie des Schwellenreizes direct als Maass für die Empfindlichkeit dient. Wir setzen also die Empfindlichkeit umgekehrt proportional der Tonintensität, welche eine gerade noch merkliche Empfindung in dem Ohre erzeugt. Die Tonintensität ist definirt als die Energie der Schallbewegung, welche durch ein Quadratcentimeter senkrecht zur Schallrichtung pro Secunde hindurch tritt. An Stelle dieser Energie kann man auch die Druckdifferenzen der Schallbewegung bestimmen, aus denen sich die Energie leicht berechnen lässt. Und zwar ist (vgl. Anhang I S. 46) die Energie $=1,19 . J^{2} \cdot 10^{10} \mathrm{Erg}$., worin $\Delta=\frac{\delta p}{p}$ die relative Druckdifferenz ist. Die Druckdifferenz $d$ eignet sich besonders gut als Maass für die Tonintensität, weil dieselbe unabhängig von der Schwingungszahl durch $\Delta$ dargestellt wird und weil die genannte einfache Relation auch bei nicht ebenen Wellen bestehen bleibt (anders für Amplituden und Geschwindigkeit der Lufttheilchen vgl. Anhang I S. 47).

In der Literatur finden sich eine Reihe von Angaben über die Sehwellenenergie für einzelne Töne, jedoch sind dieselben unter so verschiedenen Umständen erhalten, dass ein Vergleich nicht wohl möglich ist. Ich komme unten darauf zurück.

Erst in der allerneuesten Zeit sind mehrere Abhandlungen von $\mathrm{Z}$ waardemaker und $\mathrm{Quix}{ }^{1}$ ) erschienen, worin dieselben die Schwellenenergie für den ganzen Hörbereich zu bestimmen suchen. Diese Untersuchungen kamen mir erst zur Kenntniss, nacbdem ich auf der Versammlung Deutscher Naturforscher und Aerzte zu Karlsbad im vorigen Herbst über die wichtigsten Ergehnisse der vorliegenden Arbeit schon berichtet hatte. Da die Resultate von $\mathrm{Zwa}$ ardemaker und $Q u i x$ zum Theil von den meinigen sehr verschieden waren, so habe ich inzwischen meine Versuche wiederholt und erweitert, bin jedoch im Wesentlichen zu denselben Ergebnissen gelangt wie früher. Im Anhang II S. 48 sind die Arbeiten von Zwa ardemaker und $\mathrm{Qu}$ ix und die vermuthlichen Gründe unserer Differenzen ausführlich besprochen.

Die Schwierigkeiten der Untersuchung sind nicht sowohl physiologischer als physikalischer Natur und beruhen in der Bestimmung der Tonintensität. Nur wenn man die Tonquelle so einfach wie

1) Zusammengefasst in H. Zwaardemaker und F. H. Quix, Schwellenwerth und Tonböhe. Arch. f. Anat. u. Physiol. Suppl. S. 367. 1902. 
irgend möglich einrichtet und sich theoretisch alles übersehen lässt, ist daran zu denken, diese Aufgabe zu lösen.

Zur Bestimmung der Schwellenenergie eines Tones gibt es zwei Wege. 1. man misst sie direct am $\mathrm{Ohr}$; 2. man misst die Intensität der Tonquelle und berechnet, wie viel an das Ohr gelangt. Beide Wege sollen hier eingeschlagen werden. Wir beginnen mit dem ersten.

\section{Versuche, bei denen die Tonintensität am 0hre gemessen wurde (Telephonempfindlichkeit).}

Um die Empfindlichkeit des Ohres für verschiedene Schwingungszahlen festzustellen, könnte man sich etwa folgenden Versuch angestellt denken: Das Ohr wird luftdicht abgeschlossen. Die Luft in dem abgeschlossenen Raum wird durch einen von aussen hereinragenden, sich schnell hin und her bewegenden Stempel verdichtet und verdünnt. Man verkleinert die Excursionen der Stempelbewegung, bis man gerade keinen Ton mehr wahrnimmt. Wenn man nun den Stempel beliebig schnell zwischen 10 Mal und 50000 Mal in der Secunde hin und her hewegen könnte, so wäre die Aufgabe leicht zu lösen. Leider ist eine derartige Maschine nicht construirbar.

In einem bekannten Apparat haben wir aber etwas sehr Aehnliches: nämlich im Telephon. Wir drücken dasselbe, um gut hören zu können, unwillkürlich so fest an den Kopf, dass ein annähernd luftdichter ${ }^{1}$ ) Abschluss erfolgt. So lange die Dimensionen des abgeschlossenen Luftraums klein sind geven die Wellenlänge des Tones, ist an allen Stellen dieses Raumes die Verdichtung und Verdünnung dieselbe und bei gleicher Excursion der Telephonplatte unabhängig von der Schwingungszahl. Bei gleicher Plattenamplitude entsteht mithin für alle Schwingungszahlen die gleiche Tonintensitä. Wenn wir voraussetzen, dass die Telephonplatte "zwangsläufig" ist, $d$. h. dass sie für alle henutzten Schwingungszahlen der Kraft denselben Ausschlag macht wie bei einer constanten Kraft, und wenn wir ferner voraussetzen, dass durch dieselbe Stromamplitude für alle Schwingungszahlen die gleiche Kraft erzeugt wird, so wird für alle Schwingungszahlen für den gleichen Strom die gleiche Plattenamplitude und damit auch die gleiche Tonintensität erzeugt. Da nun bei schwachem Strom der Ausschlag der Platte dem Strome proportional ist, so ist

1) Wie unten bewiesen werden soll, brancht dieser Abschluss nicht vollvollkommen luftdicht zu sein, vgl. auch R a yleigh, Phil. Mag. vol. 38 p. 300.1894. 
einfach die Tonintensität proportional dem Quadrat der Stromamplitude und die Empfindlichkeit des Ohres für die jeweilige Schwingungszahl umgekehrt proportional dem Quadrat des Minimalstroms, der den Schwellenton erzeugt. Die" Empfindlichkeit des Telephons ist unter den genannten Voraussetzungen gleichzeitig ein Maass für die Empfindlichkeit des Ohres.

"Zwangsläufig" ist die Telephonplatte nur, wenn die Schwingungszahl der Kraft klein ist gegen die des tiefsten Eigentons der Platte. Die von den Telephonmagneten ausgehende Kraft hängt von der Schwingungszahl ab, weil durch die Wirbelströme im Eisen die Anzahl der magnetischen Kraftlinien vermindert wird; ein Maass dafür gibt die Selbstinduction des Telephonmagneten. Es soll weiter unten auf diese beiden Punkte näher eingegangen werden. Zunächst soll die Stromquelle, welche die Wechselströme zur Erregung des Telephons erzeugt, besprochen werden.

Erzeugung von Sinusströmen.

Vorbedingung für die Telephonversuche sind Wechselströme, deren Schwingungszahl in weiten Grenzen variirt werden kann, deren Intensität gemessen werden kann, und deren Form möglichst sinusförmig ist, damit einfache Töne erzeugt werden.

Die Ströme von $N=50$ bis $N=130$ wurde von einem Sinusinductor geliefert, von $N=200$ bis $N=1000$ von einer kleineren, von $N=1000$ bis $N=16000$ von einer grösseren Wechselstromsirene.

Der Sinusinductor war ähnlich construirt wie der F. Kohlrausch'sche, nur von grösseren Dimensionen, damit er stärkere Ströme liefern kounte. Angetrieben wurde er mittelst Schnurübertragung durch einen Elektromotor.

Die Wechselstromsirene habe ich schon mehrfach eingehend beschrieben ${ }^{1}$ ). Es genitht daher, wenn ich hier das Princip angebe.

Eine runde Scheibe aus Holz oder Messing besitzt eine Reihe von im Kreise, wie die Löcher einer Sirene, angeordneter Eisenanker. Die Scheibe dreht sich zwischen den Polen eines Magneten. Jedes Mal, wenn ein Eisenanker an den Polen vorbeikommt, ändert sich in den Polen die Zahl der magnetischen Kraftlinien, und es entsteht so in einer um die Pole gewickelten Spule ein Wechselstrom. Sind 250 Eisenanker an der Scheibe und ist die Umdrehungs-

1) Zusammengefasst: Annalen der Physik Bd. 4 S. 425.1901. 
zahl der Scheibe 30 in der Secunde, so ist die Frequenz des Wechselstroms 7500. Bis hierher ist die Art der Stromerzeugung durehaus ähnlich derjenigen, wie sie v. $\mathrm{Kriess}^{1}$ ) in seinem Inductionsapparat und Grützner" ${ }^{2}$ in seiner "Reizsirene" angewandt haben. Abgesehen von der geringen Frequenz, die mit diesen Apparaten zu erreichen ist, sind die Ströme sehr schwach und durchaus nicht sinusförmig, so dass sie sich wohl für physiologische Reizversuche, nicht aber für physikalische Messungen eignen. Dafür werden sie erst brauchbar, nachdem durch elektrische Resonanz die Intensität, wie sogleich gezeigt werden soll, ausserordentlich erhöht und der Strom von den Oberströmen gereinigt ist, so dass man einen starken, annähernd reinen Sinusstrom zur Verfügung hat. Die Intensität des Wechselstromes ist abhängig von dem „scheinbaren Widerstand “, und dieser ist wieder wesentlich durch die Selbstinduction in dem Stromkreise bedingt. Compensirt man nun die Selbstinduction durch einen passenden Condensator für die Schwingungszahl des Grundstromes, so wird dieser verstärkt, während die Oberströme, für die der scheinbare Widerstand gross bleibt, nicht mit verstärkt werden. Durch Veränderung der Tourenzahl und Verwendung von Seheiben mit verschiedener Aukerzahl konnte die Frequenz der Wechselströme zwischen 200 und 17000 variirt werden. Wegen aller Einzelheiten der Construction und Anwendung der Wechselstromsirene muss ich auf die genannte Abhandlung verweisen.

Die Anordnung bei den Versuchen war folgende: Damit das Geräusch des Motors und der Sirene nicht störte, wurde der Strom in ein entferntes ruhiges Zimmer geleitet. Die Intensität des Stromes im Hauptzweig ( $I$ Fig. 1 anf S. 8) wurde durch ein Dynamometer $(D)$ im Nebenschluss gemessen ${ }^{3}$ ). Das zu untersuchende Telephon lag in einem passenden Nebenschluss (II) zum Hauptzweig. Durch Verkleinern des Widerstandes $W_{F}$ oder Verorösssern von $W_{I I}$ konnte der Strom beliebig geschwächt werden, bis die Reizsehwelle erreicht war.

Im Allgemeinen waren die Obertöne so schwach, dass sie bei der vorliegenden Untersuchung nicht stören konnten. War jedoch ein Bedenken in diesem Punkte vorhanden, so wurde durch Einschaltung von Selbstinduction uni Capacität im Telephonkreis $(I I)$

1) J. v. Kriess, Verhandl. d. Naturf. Gesellsch. Freiburg Bu. \& S. 2. 1882.

2) P. Grutzner, Tagebl. d. 59. deutsch. Naturforscher u. s. w. S. 203. 1886.

3) M. Wien, Wiedemann's Annalen Bul. 63 s. 390. $1 \$ 97$. 
nochmals eine Reinigung des Stromes von den Oberströmen durch elektrische Resonanz bewirkt. Bei der Einstellung selbst wurde zunächst mit einem ziemlich starken Ton begonnen und derselbe ge-

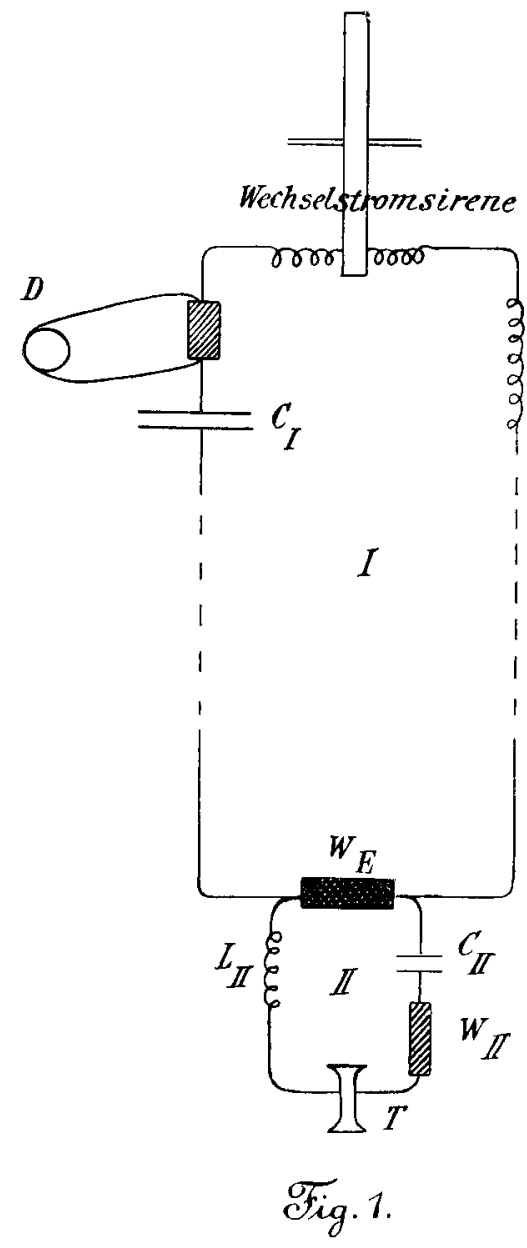
schwächt, bis er nicht mehr zu hören war. Darauf wurde er wieder verstärkt, bis er gerade wieder gehört wurde. Das Mittel aus beiden gab den Schwellenwerth. Hierbei wurde kein dauernder Ton benutzt, sondern derselbe $L_{I} \quad$ konnte durch Oeffnen und Schliessen des Stromes intermittirt werden. Dies geschah meistens durch den Beobachter selbst. Die Einstellung ist in dieser Art sehr viel sicherer wie bei einem continuirlichen Ton, da die Ermüdung des Ohres, die besonders bei hohen Tönen leicht eintritt, vermieden wird. Immerhin kamen ziemlich häufig Einstellungsdifferenzen bis zum Doppelten des Stromes, also der vierfachen Tonintensität vor. Absolute Stille brauchte bei diesen Versuchen nicht in dem Beobachtungsraum zu herrschen, da das eine Ohr durch das Telephon, das andere künstlich verschlossen wurde. Es ist dies ein-"."grosser Vorzug dieser Telephonmethode gegenüber der Bestimmung des Schwellenwerthes bei freiem Ohr.

Es sei zunächst ein Beispiel einer Einstellung hier angeführt. Telephon Bell, $N=2030$.

Amplitude im Hauptzweig Amplitude im Dynamometer $=4,6$

Reductionsfactor des Dynamometers $=6,4 \cdot 10^{-4}$. 
Ueb. die Empfindlichkeit des menschl. Ohres für Töne verschied. Höhe. 9

Ausschlag des Dynamometers $=170$,

Die Amplitude des Schwellenstromes : $\alpha_{I I}=4,6,6,4 \cdot 10^{-4} \sqrt{170} \cdot \frac{W_{E}}{W_{I I}}$ Einstellungen $\quad W_{E}=0,1, \quad W_{I I}=2850, \quad \alpha_{I I}=137 \cdot 10^{-8}$ Amp.

$W_{E}=0,1, \quad W_{I I}=3950, \quad \alpha_{I I}=96 \cdot 10^{-8}$ n

$W_{E}=0,2, \quad W_{1 I}=4750, \quad \alpha_{I I}=158 \cdot 10^{-8}$,

Im Mittel also $\alpha_{I I}=130 \cdot 10^{-8}$ Ampère.

In dieser Weise wurde die Empfindlichkeit einer Anzahl verschiedener Telephone ermittelt für die Schwingungszahlen 64 bis 16000 pro Secunde, Messungen, deren Resultate schon an anderer Stelle in anderem Zusammenhange veröffentlicht sind ${ }^{\mathbf{1}}$ ). In der Tabelle I sind die Zahlen für ein Bell'sches Telephon, ein Telephon von Apel in Göttingen und ein Telephon von Siemens \& Halske angeführt.

Tabelle I.

Empfindjichkeit verschiedener Telephone.

\begin{tabular}{|c|c|c|c|}
\hline$N$ & $\begin{array}{l}\text { B e ll } \\
\text { Anip. }\end{array}$ & $\begin{array}{l}\text { A p el } \\
\text { Amp. }\end{array}$ & $\begin{array}{c}\text { Siemens \& Halske } \\
\text { Amp. }\end{array}$ \\
\hline $\begin{array}{r}64 \\
128 \\
256 \\
512 \\
720 \\
1024 \\
1500 \\
20: 30 \\
2400 \\
2800 \\
4000 \\
8000 \\
16000\end{array}$ & $\begin{array}{r}190000 \cdot 10^{-8} \\
15000 \cdot 10^{-8} \\
1050 \cdot 10^{-8} \\
150 \cdot 10^{-5} \\
-\overline{1} \\
18 \cdot 10^{-} \\
30 \cdot 10^{-8} \\
130 \cdot 10^{-8} \\
- \\
70 \cdot 10^{-5} \\
230 \cdot 10^{-8} \\
2500 \cdot 10^{-8} \\
12000 \cdot 10^{-8}\end{array}$ & $\begin{array}{c}5000 \cdot 10^{8} \\
510 \cdot 10^{-8} \\
40 \cdot 10^{-8} \\
10 \cdot 10^{-8} \\
-\overline{10} \\
3,5 \cdot 10^{-8} \\
2,: \cdot 10^{-8} \\
8,5 \cdot 10^{-8} \\
5,0 \cdot 10^{-8} \\
70 \cdot 10^{-8} \\
70 \cdot 10^{-8} \\
1000 \cdot 10^{-8}\end{array}$ & $\begin{array}{c}1200 \cdot 10^{-8} \\
150 \cdot 10^{-8} \\
13,5 \cdot 10^{-8} \\
2,7 \cdot 10^{-8} \\
1,8 \cdot 10^{-8} \\
1,3,5 \cdot 10^{-8} \\
2,4 \cdot 10^{-8} \\
3,0 \cdot 10^{-8} \\
1,0 \cdot 10^{-8} \\
30 \cdot \overline{10} \\
400 \cdot 10^{-8} \\
1700 \cdot 10^{-8}\end{array}$ \\
\hline
\end{tabular}

Um diese Zahlen für unsere Zwecke verwerthen zu können, müssen die oben erwähnten Fehlerquellen berücksichtigt werden.

Fehlerquellen.

Zunächst müssen wir eine Correction für die durch die Wirbelströme bewirkte Verringerung der magnetischen Anziehung des Telephonelektromagneten bei höheren Schwingungszahlen einführen. Den Correctionsfactor finden wir in dem Verhältniss der Selbstinduction für die verschiedenen Schwingungszahlen $\left(L_{N}\right)$ zu dem für sehr lang-

1) M. Wien, Annalen der Physik Bd. 4 s. 456.1901. 
same Schwingungen $\left(L_{0}\right)$. Es ist dann also $\alpha_{I L}^{\prime}=\alpha_{I I} \frac{L_{N}}{L_{\theta}}$. Ueber die Aenderung der Selbstpotentiale der Telephone mit der Schwingungszahl mag folgende Tabelle ein Bild geben, die ebenfalls der erwähnten Arbeit entnommen ist:

Tabelle II.

Selbstpotential der Telephone.

\begin{tabular}{r|c|c|c}
\hline \multicolumn{1}{c}{$N$} & $\begin{array}{c}\text { Bell } \\
\text { Amp. }\end{array}$ & $\begin{array}{c}\text { A p el } \\
\text { Amp. }\end{array}$ & $\begin{array}{c}\text { Siemens \& Halske } \\
\text { Amp. }\end{array}$ \\
\hline 256 & $3,53 \cdot 10^{6}$ & $3,73 \cdot 10^{7}$ & $1,93 \cdot 10^{8}$ \\
1000 & $3,28 \cdot 10^{6}$ & $3,08 \cdot 10^{7}$ & $1,23 \cdot 10^{8}$ \\
4000 & $2,75 \cdot 10^{6}$ & $2,50 \cdot 10^{7}$ & $0,88 \cdot 10^{8}$ \\
8000 & $2,42 \cdot 10^{6}$ & $1,96 \cdot 10^{7}$ & $0,68 \cdot 10^{8}$ \\
16000 & $2,16 \cdot 10^{6}$ & $1,63 \cdot 10^{7}$ & $0,58 \cdot 10^{8}$
\end{tabular}

Eine andere Fehlerquelle könnte dadurch bedingt sein, dass beim Andrücken des Telephons an das Ohr der Luftabschluss kein vollkommener ist. Die übrig bleibenden Oeffnungen könnten nun bei verschiedenen Schwingungszahlen die Luftdruckdifferenzen im Innern verschieden beeinflussen.

Um dies zu untersuchen, wurden bei dem Telephon von Siemens \& Halske Parallelversuche gemacht, das eine Mal in der gewöhnlichen Art, das andere $\mathrm{Mal}$, indem die Oeffnung des Telephons durch einen durchbohrten Kautschuckstöpsel mit einer kurzen, passenden Glasröhre verschlossen war, die luftdicht in das Ohr gesteckt wurde. Tabelle III gibt die Resultate.

Tabelle III.

\begin{tabular}{|c|c|c|c|c|}
\hline$N$ & $\begin{array}{l}\text { A. } V . \\
\text { Amp. }\end{array}$ & $\begin{array}{l}N . V . \\
\text { Amp. }\end{array}$ & $\begin{array}{c}H . \\
\text { Amp. }\end{array}$ & $\begin{array}{l}2 H . \\
\text { Amp. }\end{array}$ \\
\hline $\begin{array}{r}256 \\
600 \\
4000 \\
8000\end{array}$ & $\begin{array}{c}13,5 \cdot 10-8 \\
2,0 \cdot 10-8 \\
30 \cdot 10-8 \\
400 \cdot 10-8\end{array}$ & $\begin{array}{c}8 \cdot 10-8 \\
1,6 \cdot 10-8 \\
25 \cdot 10-8 \\
190 \cdot 10-8\end{array}$ & $\begin{array}{c}5 \cdot 10-8 \\
0,8 \cdot 10-8 \\
9 \cdot 10^{-8} \\
180 \cdot 10-8\end{array}$ & $\begin{array}{c}10 \cdot 10-8 \\
1,6 \cdot 10-8 \\
18 \cdot 10-8 \\
360 \cdot 10-8\end{array}$ \\
\hline
\end{tabular}

Unter $A . V$. sind die Werthe der alten Versuchsreihe, die oben angeführt ist (Tabelle I), zu verstehen, unter $N . V$. die in derselben Weise erhaltenen der neuen Versuchsreihe, die über ein Jahr später gemacht wurde. Sie unterscheiden sich nur wenig, vielleicht zeigt 
Ueb. die Empfindlichkeit des menschl. Ohres für 'Töne verschied. Höhe.

die neue Versuchsreihe eine etwas grössere Empfindlichkeit des Ohres an, die allmählich durch die Uebung erzielt ist. Die Zahlen "H" sind gleichzeitig "mit Hörrohr" erhalten; sie verlaufen relativ in derselben Weise wie $N . \quad V$. , jedoch sind die absoluten Werthe etwas kleiner. Es dürfte dies daher rühren, dass der abgeschlossene Luftraum kleiner ist, als wenn man das Telephon an's Ohr drückt. Nehmen wir den Luftraum als halb so gross an, so hat man $2 H$ als zu vergleichende Werthe des Stromes zu nehmen; offenbar stimmen die Werthe damn innerhalb der Fehlergrenzen mit $N$. $V$. überein.

Die später verwandten Telephone wurden stets mit einem geeigneten Deckel versehen, der einen etwa 2 cm langen Ansatz hatte, welcher in das Ohr gesteckt wurde (vgl. Fig. 4 S. 16).

Von den oben genannten Fehlerquellen bleibt nun noch der Einfluss der Eigentöne der Platte übrig, der weiter unten sogleich besprochen werden soll. Zunächst nehmen wir an, dass die Platte „zwangläufig" sei, d. h. dass sie für alle Schwingungszahlen für den gleichen Strom den gleichen Ausschlag macht. Dann ist einfach die Druckdifferenz in dem abgeschlossenen Raum proportional der Stromamplitude $\alpha_{I I}^{\prime}=\alpha_{I I} \cdot \frac{L_{N}}{L_{0}}$, die Tonintensität proportional

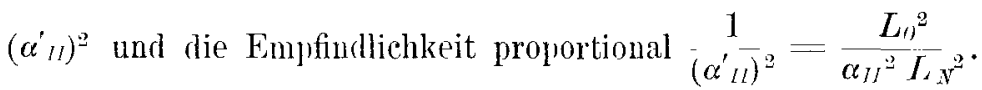

Es kommen nun unter den Zahlen der Tabelle I fur dasselhe Telephon Verhältnisse der Ströme von 1: 10000), also Verhältnisse der Empfindlichkeit von $1: 10^{\circ}$, vor. Das gibt ganz unübersichtliche Zahlen und kann vor Allem nicht graphisch aufgetragen werden. In der Tab. IV sind desshalb unter $E^{\prime}$ nicht diese Zahlen selbst, sondern ihre Logarithmen bezogen auf die Basis 10 , also $\lg \cdot\left(\frac{L_{t^{2}}{ }^{2}}{\alpha_{I I}{ }^{2} \cdot L_{Y^{2}}}\right)$ angegeben. Insofern hat die Darstellung durch die Logarithmen auch eine innere Berechtigung, als nach dem Weber-Fechner'schen Gesetz die Empfindung mit dem Logarithmus des Reizes wächst.

Die Werthe von $E^{\prime}$ geben also - abgesehen von der Wirkung der Figentöne - für jedes Telephon den Verlauf der Empfindlichkeit mit der Tonhöhe an, unter einander sind jedoch die Werthe bei den drei Telephonen noch nicht vergleichbar, da wegen der verschiedenen Bauart und der versehiedenen Widerstände die absoluten Zahlen verschieden sind. Um dies auszugleichen, müssen additive Constante hinzu- 
gefügt werden, die die drei Curven möglichst zur Deckung bringen, dann erst kann man ihren Verlauf vergleichen. Im Folgenden ist nun bei den drei Telephonen der Werth für $N=256$ gleich gemacht, und zwar $=10,0$, dem Werth bei dem Bell'schen Telephon. Dazu muss von den Zahlen für $E^{\prime}$ bei dem Apel'schen Telephon 2,8, bei dem Sommer'schen Telephon 3,8 abgezogen werden. Man erhält dann die unter $E$ angegebenen Zahlen. Es sei hier und im folgenden die "logarithmische Empfindlichkeit" genannt, ist also = dem Brigg'schen Logarithmus der "wahren Empfind lichkeit", die mit $\left(E\right.$ bezeichnet werden soll $\left(\xi=10^{k}\right)$.

Tabelle IV.

Logarithmische Empfindlichkeit der Telephone.

\begin{tabular}{|c|c|c|c|c|c|c|}
\hline \multirow{2}{*}{$N$} & \multicolumn{3}{|c|}{$E^{\prime}$} & \multicolumn{3}{|c|}{$E$} \\
\hline & B e 11 & Apel & Siemens & B e 11 & A pel & Siemens \\
\hline 64 & 5,5 & 8,6 & 9,8 & 5,5 & 5,8 & 6,0 \\
\hline 128 & 7,7 & 10,6 & 11,6 & 7,7 & 7,8 & 7,8 \\
\hline 256 & 10,0 & 12,8 & 13,8 & 10,0 & 10,0 & 10,0 \\
\hline 512 & 11,7 & 14,1 & 15,3 & 11,7 & 11,3 & 11,5 \\
\hline 720 & - & & 16,5 & & - & 12,7 \\
\hline 1024 & 13,6 & 15,1 & 16,1 & 13,6 & 12,3 & 12,3 \\
\hline 1500 & 13,4 & 15,5 & 15,7 & 13,4 & 12,7 & 11,9 \\
\hline 2030 & 11,9 & 15,2 & 15,6 & 11,9 & 12,4 & 11,8 \\
\hline 2400 & - & - & 16,6 & & - & 12,8 \\
\hline 2800 & 12,5 & - & - & 12,5 & - & \\
\hline 4000 & 11,5 & 12,7 & 13,8 & 11,5 & 9,9 & 10,0 \\
\hline 8000 & 9,6 & 12,1 & 11,8 & 9,6 & 9,3 & 8,0 \\
\hline 16000 & 8,3 & 10,7 & 10,6 & 8,3 & 7,9 & 6,8 \\
\hline
\end{tabular}

In der Fig 2 ist die logarithmische Empfindlichkeit $E$ graphisch aufgetragen, die ausgezogene Curve gilt für das Bell'sche, die punktirte für das A pel'sche, die gestrichelte für das Si emens'sche Telephon. An die Ordinatenaxe ist jedoch nicht $E$, sondern die wahre Empfindlichkeit $\left(E=10^{E}\right)$ angeschrieben, um auf die eigentliche Bedeutung der Curven hinzuweisen. Bis zu $N=500$ verlaufen die Curven annähernd glejch; dann beginnen sie jedoch stark auseinander zu gehen, um an verschiedenen Stellen ein oder mehrere Maxima zu zeigen. Diese Maxima fallen im allgemeinen ${ }^{1}$ ) mit den Eigentönen der Platten zusammen, wie die folgende Tabelle zeigt, welche die beim directen Hören gefundenen Eigentöne der Platten angibt.

1) Ausser bei dem Apel'schen Telephon, wo sie wegen starker Dämpfung nur wenig hervortreten. 


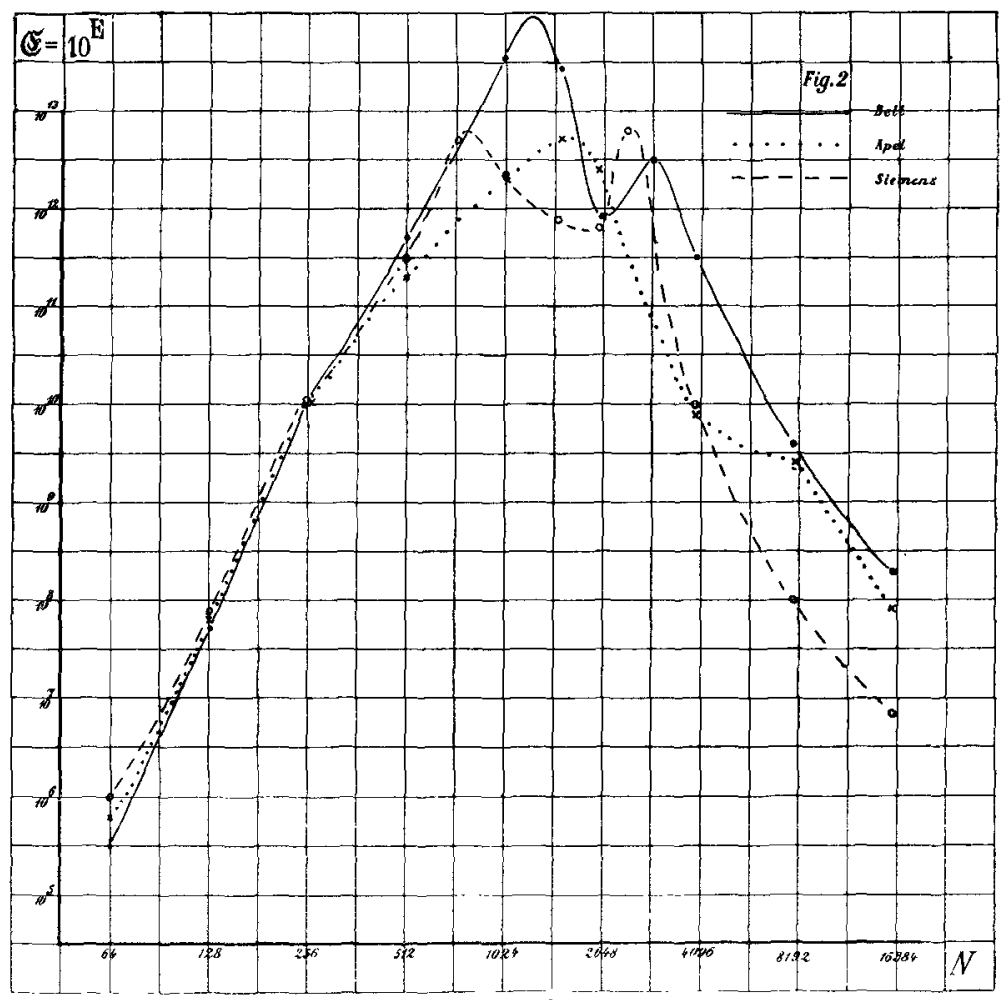

Fig. 2.

Tabelle V.

Eigentöne der Telephone.

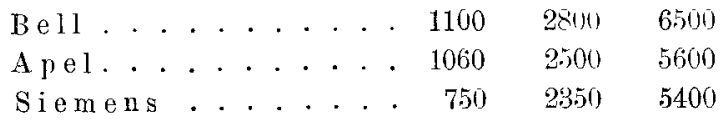

Einfluss der Eigentöne der Telephonplatte.

Für die vorliegende Frage ist es hauptsächlich wichtig, zu wissen, wie weit die Platten zwangsläufig sind, $d . h$. für welchen Bereich von Schwingungszahlen man annehmen kann, dass die Plattenamplitude bei gleicher Stromamplitude gleich ist.

Der Theorie nach ist die Amplitude der elastischen Schwingung eines Punktes von der Eigenperiode $p$ und der Dämpfung $h$, auf den eine Kraft $f$ von der Periode $n$ in $2 \pi$ Secunden wirkt, durch die Gleichung gegeben:

$$
a=\frac{F}{\sqrt{\left(n^{2}\right.}-\frac{F}{\left.p^{2}\right)^{2}}+n^{2} h^{2}}
$$


Ist $p$ gross gegen $n$, so ist $a$ annähernd $=F / p^{2}$, also unabhängig von der Periode der Kraft, für $n=p$ wird $\alpha$ ein Maximum, wenn $n$ grösser wird als $p$, nimmt die Amplitude schnell ab.

Um diese Frage direct experimentell zu untersuchen, wurde die Amplitude des Bell'schen Telephons für verschiedene Schwingungszahlen des erregenden Stromes mikroskopisch gemessen. Und zwar wurde das Telephon in der Form untersucht, in der es im Abschnitt II verwandt wurde. Dabei war die freie Fläche der Platte etwas grösser, und der Telephonmagnet war sehr nahe herangeschraubt, um die Excursionen zu vergrössern. Ausserdem war, um die Anplutide mit dem Mikroskop beobachten zu können, ein kleines, dünnes Glasfädchen mit Siegellack in der Mitte der Platte aufgeklebt. Alles dieses vertiefte etwas die Eigentöne der Platte, so dass der erste bei $N=945$ statt wie vorher bei $1100 \mathrm{lag}$.

Die Beobachtung geschah mit einem Zeiss'schen Mikroskop, von ca. 600 facher linearer Vergrösserung. Es wurde auf irgend einen passenden kleinen, hellen Punkt in dem Bilde des Glasfadens eingestellt; wenn ein Wechselstrom durch das Telephon ging, wurde aus dem Punkt eine Linie, deren Länge mit Hülfe einer Okulartheilung (Scalentheil $=1 / 385 \mathrm{~mm}$ ) gemessen wurde. Aus optischen

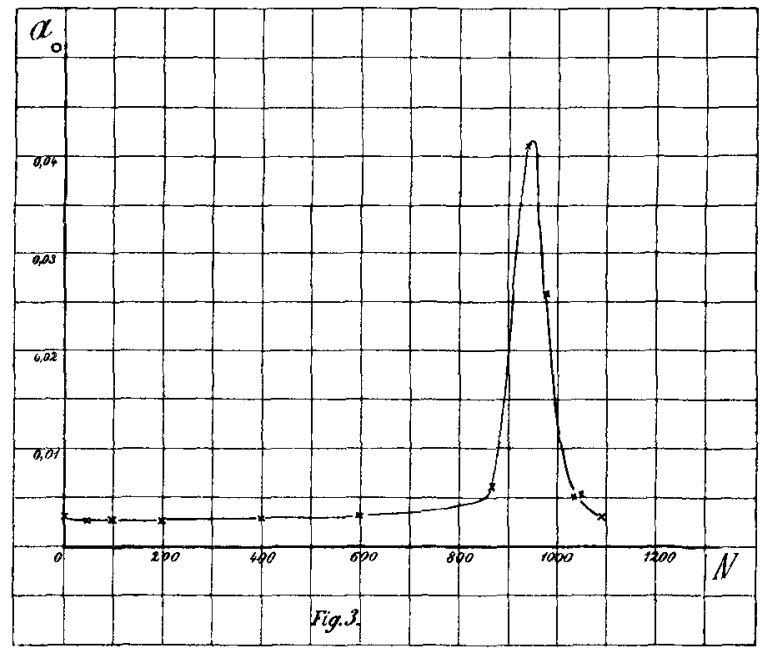

Fig. 3.

Gründen war die Mesšung ziemlich schwierig und unsicher, immerhin konnte die Amplitude auf etwa 5 bis $10 \%$ festgestellt werden. Bis etwa 5/100 Ampère wuchs der Ausschlag proportional der Strom- 
amplitude, dann schneller als diese, weil die magnetische Induction im Telephonmagneten schneller zunahm. Die Resultate sind in der folgenden Tabelle angegeben und in Fig. 3 eingetragen.

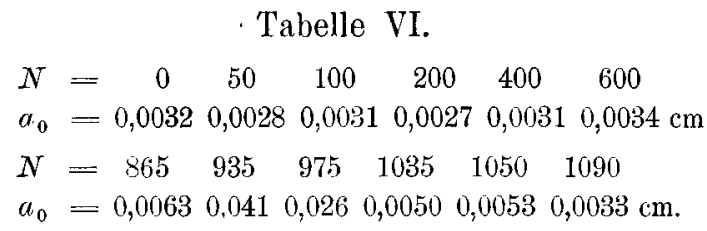

Tabelle und Curve ergeben, dass entsprechend der Theorie die Telephonausschläge bis in die Nähe des ersten Figentons der Platte merklich unabhängig von der Schwingungszahl sind. Der Weg für die Untersuchung ist hiermit vorgeschrieben. Die Platten geben nur insoweit richtige Ergebnisse für die Tonempfindlichkeit, als Schwingungen mit ihnen untersucht werden, die tiefer sind als ihr erster Eigenton. Im Folgenden wurde daher der Eigenton der Platten immer weiter erhöht, indem die Platte kleiner und dicker genommen wurde. Die eigentliche Untersuchung wurde mit folgenden vier Telephonen ausgeführt:

Telephon I. Das oben untersuchte Bell'sche Telephon, Plattenradius $1,9 \mathrm{~cm}$, Plattendicke $0,018 \mathrm{~cm}$.

Tiefster Eigenton: 110\%.

'Telephon II. Dassclbe Telephon wie I, nur andere I'latte, Plattenradius $1,0 \mathrm{~cm}$, Plattendicke $0,02 \mathrm{~cm}$.

Tiefster Eigenton: 2900.

Telephon III. Neues wesentlich kleineres Telephon (Fig. 4). Die Platte ist fest zwischen geschliffenen Messingringen eingeschraubt. Plattenradius $0,5 \mathrm{~cm}$, Plattendicke $0,008 \mathrm{~cm}$.

Tiefster Eigenton: 5500.

Telephon IV. Dasselbe Telephon wie III, nur andere Platte. Plattenradius $0,5 \mathrm{~cm}$, Plattendicke $0,02 \mathrm{~cm}$.

Tiefster Eigenton: 12000 .

Es gelang der Kunst meines treuen Mitarbeiters, des hiesigen Institutsmechanikers Herm Feldhausen, ein noch kleineres Telephon herzustellen:

Telephon V. Plattenradius $0,25 \mathrm{~cm}$, Plattendicke 0,008 .

Tiefster Eigenton über 20000. 
Jedoch wurde dasselbe erst bei den Untersuchungen im Theil II benutzt, da es bei den vorliegenden Beobachtungen wegen einer

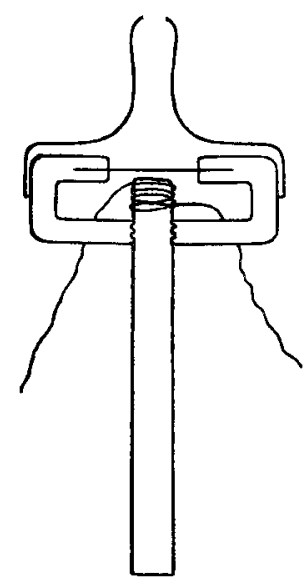

Fig. 4 . anderen Fehlerquelle keinen Zweck hatte, zu noch böheren Tönen überzugehen. Es ist nämlich oben vorausgesetzt, dass der von der Telephonplatte abgeschlossene Luftraum kleine Dimensionen haben sollte gegen die Wellenlänge des zu untersuchenden Tones. Für $N=10000$ erhalten wir bei Zimmertemperatur die Wellenlänge $=3,4 \mathrm{~cm}$. Obgleich nun der Ansatz an dem Deckel des Telephons (vgl. Fig 4) tief in den Gehörgang gesteckt werde, so dass die Platte unmittelbar am Eingang des Ohres lag, so ist doch schon die Länge des äusseren Gehörganges allein von derselben Grössenordnung wie die Wellenlänge. Es liegt hier also eine Fehlerquelle vor, die bei dieser Methode die Ergebnisse für die ganz hohen Töne unsicher erscheinen lässt.

\section{Versuchsresultate.}

Die Resultate der Versuche sind in den folgenden Tabellen gegeben. Es bezieht sich alles auf mein rechtes Ohr. Unter $\boldsymbol{\alpha}_{I I}$ ist die Amplitude des Minimalstromes angegeben, die Zahl ist stets das Mittel aus zwei oder drei Versuchen. $L_{N}$ ist die Selbstinduction des betreffenden Telephons für die verschiedenen Schwingungszahlen. $\quad E^{\prime}=\lg \frac{L_{0}^{2}}{\alpha_{I I}^{2} L_{N^{2}}{ }^{2}}$ die relative logarithmische Empfindlichkeit. $E$ die logarithmische Empfindlichkeit, bezogen auf das Telephon I. Die Ergebnisse für das Telephon I, welche unter "Be11" schon in der Tabelle I und IV angegeben sind, seien hier der Vollständigkeit halber nochmals reproducirt. 
Ueb. die Empfindlichkeit des menschl. Ohres für Töne verschied. Höhe.

Tabelle VII.

(Bell'sches) Telephon I. Tiefster Eigenton 1100.

$$
E=E^{\prime} \text {. }
$$

\begin{tabular}{r|c|c|r|r}
\hline$N$ & $\boldsymbol{\alpha}_{I I}$ & $L_{N}$ & $E^{\prime}$ & $E$ \\
\hline & $1,9 \cdot 10-3$ & $3,7 \cdot 10^{6}$ & 5,5 & 5.5 \\
128 & $1,5 \cdot 10-4$ & $3,6 \cdot 10^{6}$ & 7,7 & 7,7 \\
256 & $1,05 \cdot 10-5$ & $3,5 \cdot 10^{6}$ & 10,0 & 10,0 \\
512 & $1,5 \cdot 10-6$ & $3,4 \cdot 10^{6}$ & 11,7 & 11,7 \\
1024 & $1,8 \cdot 10-7$ & $3,2 \cdot 10^{6}$ & 13,6 & 13,6 \\
1500 & $3,0 \cdot 10-7$ & $3,1 \cdot 10^{6}$ & 13,4 & 13,4 \\
2030 & $1,3 \cdot 10-6$ & $3,0 \cdot 10^{6}$ & 11,9 & 11,9 \\
2800 & $7,0 \cdot 10-7$ & $2,9 \cdot 10^{6}$ & 12,5 & 12,5 \\
4000 & $2,3 \cdot 10-6$ & $2,7 \cdot 10^{6}$ & 11,5 & 11,5 \\
8000 & $2,5 \cdot 10-5$ & $2,4 \cdot 10^{6}$ & 9,6 & 9,6 \\
16000 & $1,2 \cdot 10-4$ & $2,2 \cdot 10^{6}$ & 8,3 & 8,3
\end{tabular}

Tabelle VIII.

Telephon II. Tiefster Eigenton 2900. $E=E^{\prime}+0,3$.

\begin{tabular}{|c|c|c|c|c|}
\hline$N$ & $\boldsymbol{\alpha}_{I I}$ & $L_{X^{r}}$ & $E^{\prime}$ & $E$ \\
\hline $\begin{array}{r}50 \\
100 \\
200 \\
400 \\
8100 \\
1600 \\
2 \times 100 \\
3200 \\
5000\end{array}$ & $\begin{array}{l}5,5 \cdot 10-3 \\
3,2 \cdot 10-4 \\
2,1 \cdot 10-5 \\
2,0 \cdot 10-6 \\
9,11 \cdot 10-7 \\
4,5 \cdot 10-7 \\
1,2 \cdot 10-7 \\
3,1 \cdot 10-7 \\
1,35 \cdot 10-6\end{array}$ & $\begin{array}{l}3,7 \cdot 10^{6} \\
3,7 \cdot 10^{6} \\
3,6 \cdot 10^{6} \\
3,5 \cdot 10^{6} \\
3,4 \cdot 10^{6} \\
3,1 \cdot 10^{6} \\
2,9 \cdot 10^{6} \\
2,4 \cdot 10^{6} \\
2,5 \cdot 10^{6}\end{array}$ & $\begin{array}{r}4,5 \\
7,0 \\
9,4 \\
11,4 \\
12,2 \\
12,8 \\
14,1 \\
13, ; \\
12,0\end{array}$ & $\begin{array}{r}4,8 \\
7,3 \\
9,7 \\
11,7 \\
12,5 \\
13,1 \\
14,4 \\
13,6 \\
12,3\end{array}$ \\
\hline
\end{tabular}

Tabelle IX.

Telephon III. Tiefster Eigenton 5500. $E=E^{\prime}-0,5$.

\begin{tabular}{|c|c|c|c|c|}
\hline$N$ & $\alpha_{I I}$ & $L_{V}$ & $E^{\prime}$ & $E^{\top}$ \\
\hline $\begin{array}{r}50 \\
100 \\
200 \\
400 \\
800 \\
1600 \\
4000 \\
5000 \\
6000 \\
8000\end{array}$ & $\begin{array}{l}1,3 \cdot 10-3 \\
1,4 \cdot 10-4 \\
1,5 \cdot 10-5 \\
1,5 \cdot 10-6 \\
5,1 \cdot 10-7 \\
2,0 \cdot 10-7 \\
4,0 \cdot 10-7 \\
7,3 \cdot 10-8 \\
2,6 \cdot 10-8 \\
6,0 \cdot 10-7\end{array}$ & $\begin{array}{l}1,43 \cdot 10^{7} \\
1,40 \cdot 10^{7} \\
1,35 \cdot 10^{7} \\
1,25 \cdot 10^{7} \\
1,10 \cdot 10^{7} \\
0,95 \cdot 10^{7} \\
0,75 \cdot 10^{7} \\
0,70 \cdot 10^{7} \\
0,66 \cdot 10^{7} \\
0,59 \cdot 10^{7}\end{array}$ & $\begin{array}{r}5, \\
7,7 \\
9,7 \\
11,8 \\
12,8 \\
19,8 \\
13,3 \\
14,9 \\
15,8 \\
13,2\end{array}$ & $\begin{array}{r}5,3 \\
7,2 \\
9,2 \\
11,3 \\
12,3 \\
13,3 \\
12,8 \\
14,4 \\
15,3 \\
12,8\end{array}$ \\
\hline
\end{tabular}


Tabelle X.

Telephon IV. Tiefster Eigenton 12000. $E=E^{\prime}+2,0$.

\begin{tabular}{r|c|c|r|r}
\hline$N$ & $\alpha_{I T}$ & $L_{N}$ & $E^{\prime}$ & $E$ \\
\hline 50 & $1,35 \cdot 10-2$ & $1,43 \cdot 10^{7}$ & 3,7 & 5,7 \\
100 & $3,4 \cdot 10-3$ & $1,40 \cdot 10^{7}$ & 5,0 & 7,0 \\
200 & $3,4 \cdot 10^{-4}$ & $1,35 \cdot 10^{7}$ & 7,0 & 9,0 \\
400 & $3,1 \cdot 10^{-5}$ & $1,25 \cdot 10^{7}$ & 9,1 & 11,1 \\
800 & $4,2 \cdot 10-6$ & $1,10 \cdot 10^{7}$ & 11,0 & 13,0 \\
1600 & $2,8 \cdot 10-6$ & $0,95 \cdot 107$ & 11,5 & 13,5 \\
3200 & $2,9 \cdot 10-6$ & $0,85 \cdot 10^{7}$ & 11,6 & 13,6 \\
4000 & $1,0 \cdot 10^{7}-5$ & $0,75 \cdot 10^{7}$ & 10,6 & 12,6 \\
6000 & $1,7 \cdot 10-5$ & $0,66 \cdot 10^{7}$ & 10,3 & 12,3 \\
8000 & $1,25 \cdot 10-5$ & $0,59 \cdot 10^{7}$ & 10,2 & 12,2 \\
12000 & $1,6 \cdot 10^{-5}$ & $0,53 \cdot 10^{7}$ & 10,6 & 12,6 \\
16000 & $3,6 \cdot 10^{-5}$ & $0,50 \cdot 10^{7}$ & 9,8 & 11,8 \\
& & & &
\end{tabular}

Tabelle XI.

Zusammenstellung der Werthe von $E$ für alle 4 Telephone.

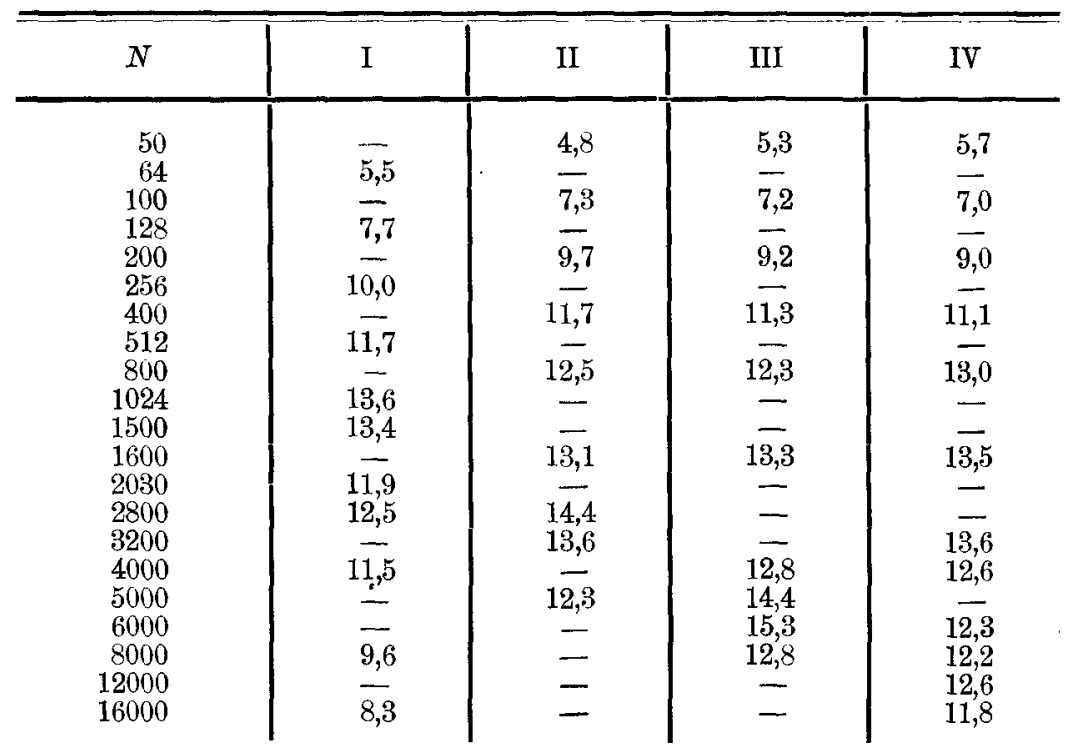

Die Resultate sind in Fig. 5 graphisch aufgetragen, und zwar sind die Zahlen für Telephon I durch . . ., die von II durch $\times \times \times$, von III durch $\bigcirc \bigcirc \bigcirc$, von IV durch $\odot \odot \odot$ bezeichnet. Die Curven sind einfach durch gerade Verbindungslinien der beobachteten Punkte 
Ueb. die Empindlichkeit des menschl. Ohres für Töne verschied. Höhe.

erhalten. Die für Telephon I und III sind ausgezogen, II ist gestrichelt und IV punktirt. Die Beobachtungen sind bei allen Telephonen über den tiefsten Eigenton der Platte hinaus fortgesetzt. Derselbe macht sich überall durch ein mehr oder weniger ausgesprochenes Maximum bemerkbar.

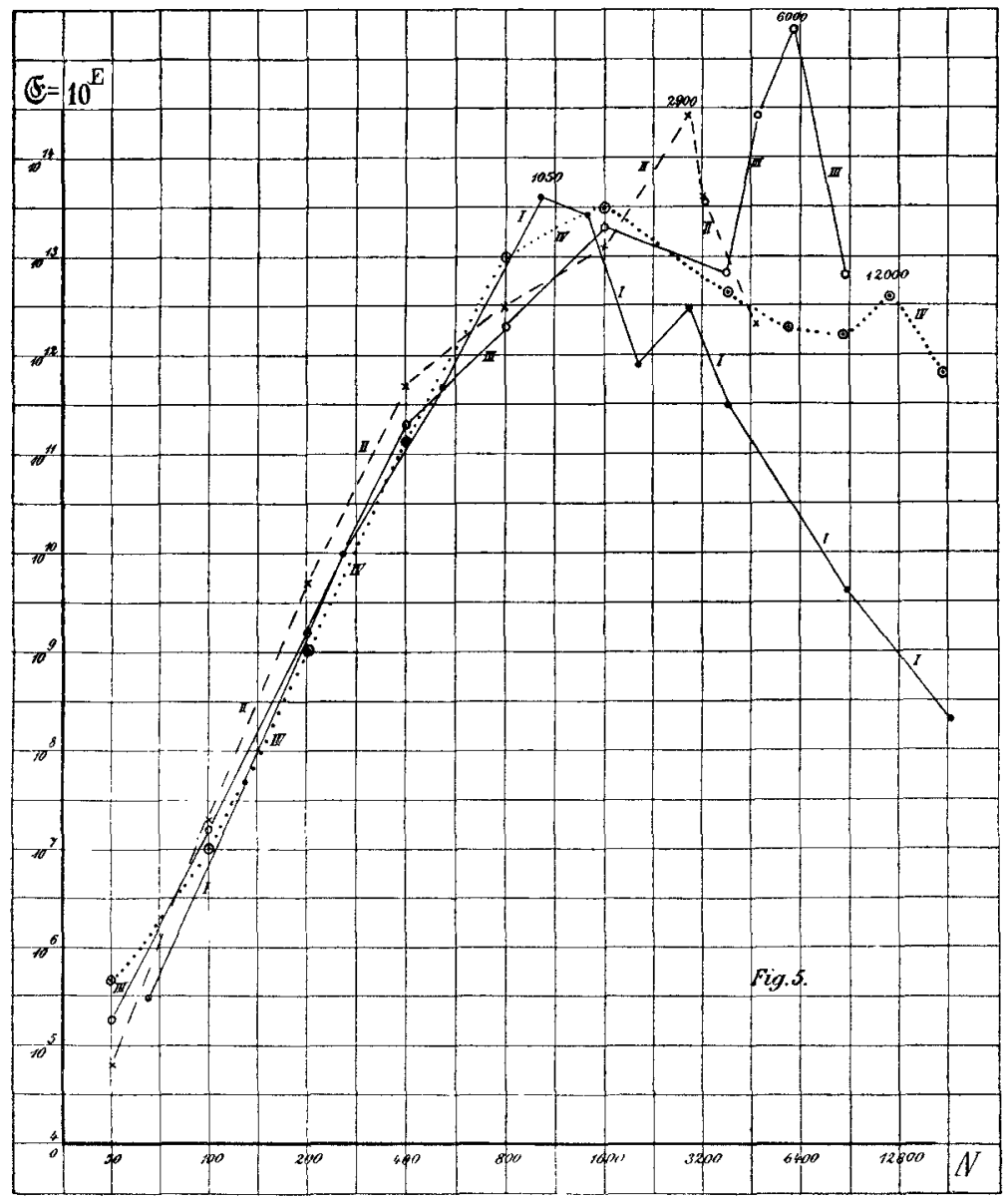

Fig. 5.

Bis in die Nähe dieses Eigentons laufen die Curven innerhalb der Fehlergrenzen zusammen. Es wird dies deutlicher aus Figur 6 hervorgehen. Die Beobachtungen sind hier für jedes Telephon nur bis in die Nähe des Eigentons eingetragen. Die Curve stellt den Mittelwerth aller Beohachtungen dar. Die Abweichungen sind nur im letzten Theil, bei den ganz hohen 
Tönen, erheblicher, wo, wie gesagt, wegen der kleinen Wellenlänge die Telephonmethode unsicher ist. Vor der Besprechung der Resultate seien zunächst die Versuche nach Methode II dargestellt.

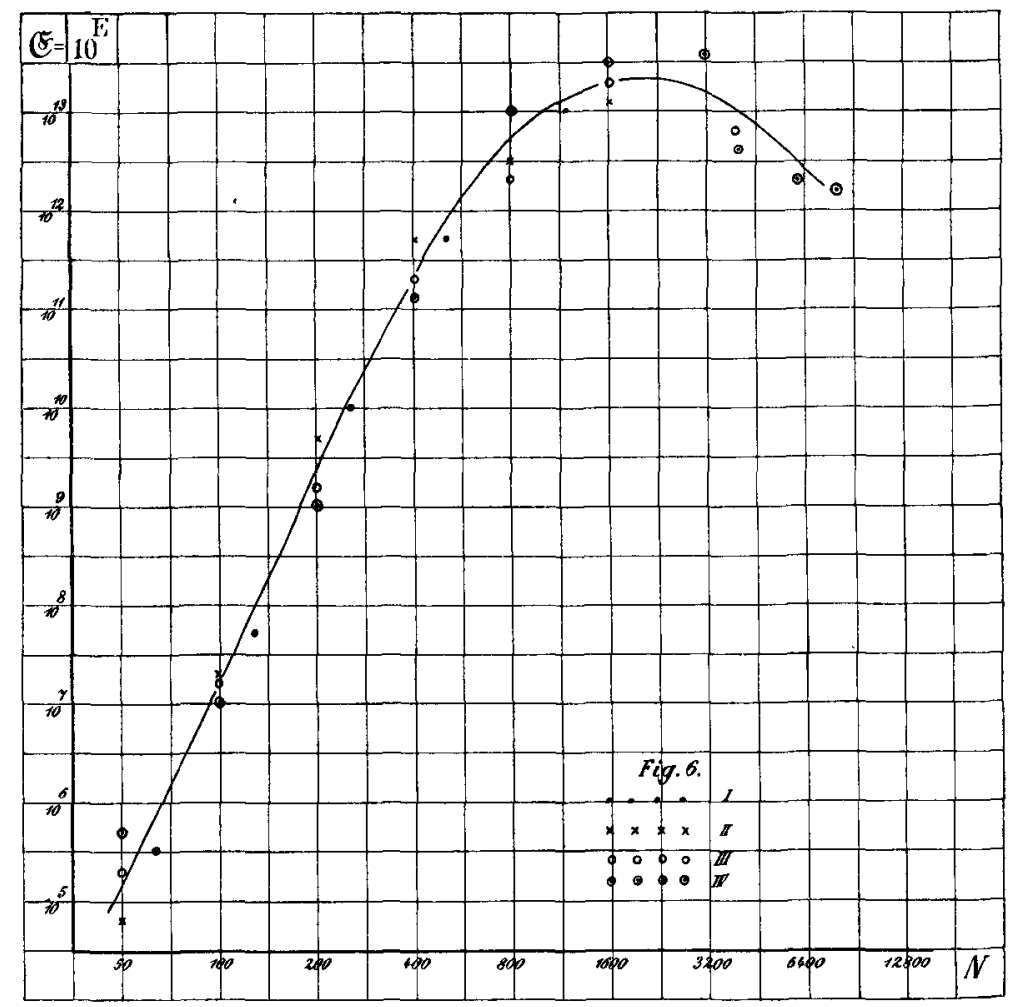

Fig. 6.

\section{Versuche, bei denen die Intensität der Tonquelle gemessen wurde.}

Helmholtz hat gezeigt, wie man die Schallintensität an irgend einem Orte ausserhalb berechnen kann, wenn man die Luftbewegung an der Mündung einer Pfeife kennt. In ähnlicher Weise lässt sich auch die von einer schwingenden Platte an irgend einem entfernten Orte erzeugte Tonintensität berechnen, wenn man die Bewegung der Platte kennt.

Diese Aufgabe ist im Anhang I (S. 41) gelöst unter der Voraussetzung, dass die Platte sinusförmige erzwungene Schwingungen macht, dass sie ein Theil einer festen Ebene ist, die den Raum in 
zwei Hälften theilt, und dass die Entfernung zwischen Platte und Ohr gross ist gegen die Dimensionen der Platte.

Das Resultat der Theorie ist folgendes:

Ist $a_{0}$ die Amplitude der Mitte der runden Platte, $R$ ihr Radius, $\varrho$ die Entfernung zwischen Ohr und Platte, $c$ die Schallgeschwindigkeit und $k$ das Verhältniss der specifischen Wärmen, so ist die relative Druckamplitude

$$
\Delta=0,147 \cdot \frac{k}{c^{2}} \cdot \frac{(2 n N)^{2} R^{2} a_{0}}{\varrho}
$$

und die Tonintensität, also die Energie, welche in einer Sekunde durch $1 \mathrm{qcm}$ senkrecht zur Schallrichtung hindurchgeht:

$$
A=\frac{c p_{0}}{2 k} \Delta^{2}=1,19 \cdot 10^{10} \Delta^{2} \text { Erg. }
$$

Um den Voraussetzungen der Theorie möglichst nachzukommen, wurden die Versuche so angestellt, dass der obere Theil des Holzgehäuses eines Bell'schen Telephons entfernt und dafür die Platte mittelst eines Messingringes festgeklemmt wurde. Das so eingerichtete Telephon wurde dann auf einem grossen Blech, das in der Mitte ein Loch von der Grösse der Telephonplatte besass, befestigt, so dass die Platte in die Ehene des Bleches fiel (Fig. 7). Das Ohr wurde der Mitte der Platte gegenüber in einer Entfernung $\varrho=30 \mathrm{~cm}$ gehalten. Der Plattenradius $R$ betrug $2 \mathrm{~cm}$, war also klein gegen $\varrho$.

In dem Ausdruck für $d$ kommt die Schwingungszahl $N$ im Quadrat vor; da die Intensität $A$ proportional $J^{2}$ ist, so wächst sie bei gleicher Amplitude der Platte proportional der vierten Potenz der Schwingungszahl, so dass ein Ton von 15000 Schwingungen bei gleicher Amplitude der Platte mit der $3000^{4}=8,1 \cdot 10^{9}$ fachen Intensität das Ohr träfe wie ein Ton von 50 Schwingungen in der Secunde. Diese Art der Erzeugung und Messung der Tonintensität unterscheidet sich also sehr wesentlich von der oben angewandten, wo die Tonintensität bei gleicher Amplitude der Telephonplatte von der Schwingungszahl unablı̈ngig war. Für unsere Untersuchung, die ja gerade den Zweck hat, die Abhängigkeit der Empfindlichkeit des menschlichen Ohres von der Schwingungszahl festzustellen, ist dieser Unterschied in den beiden Methoden der Intensitätsmessung ein Vorzug: wenn sie beide das Gleiche ergeben, so gibt gerade die verschiedene Abhängigkeit von der Schwingungszahl dem Ergebniss eine erböhte Sicherheit. 
Für die Anwendung der Methode jedoch bedingt der starke Abfall der Tonintensität mit der Schwingungsdauer mancherlei Schwierigkeiten.

Es konnte nicht etwa mit einem kleinen Telephon mit sehr hohem Eigenton der Platte der ganze Tonbereich $(N=50$ bis
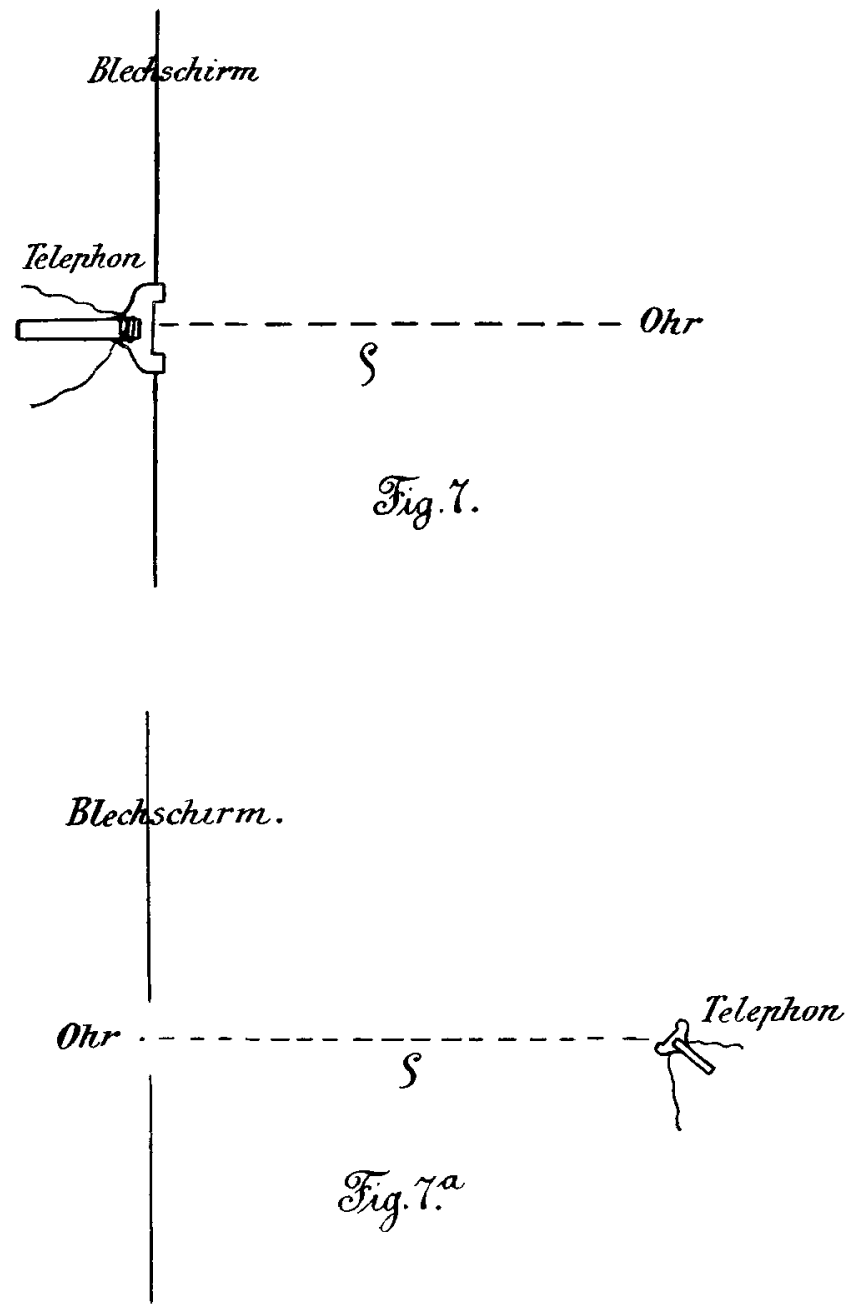

$N=15000$ ) untersucht werden. Dazu war für die tieferen Töne die erreichbare Intensität viel zu gering. Und auch bei dem eben genannten Bell'schen Telephon von $2 \mathrm{~cm}$ Plattenradius konnte nicht mit der Schwingungszahl unter $N=200$ hinuntergegangen werden. 
Ueb. die Empfindlichkeit des menschl. Ohres für Töne verschied. Höhe. 23

Zwar war der mit starken Sinusströmen erzeugte Ton noch laut genug, jedoch ist bei diesen starken Strömen die Bewegung der Telephonplatte auch bei reinen Sinusströmen nicht mehr sinusförmig, weil die Anziehung einseitig ist, und weil die magnetische Induction nur in gewissen Grenzen dem Strom proportional wächst. Dadurch entstehen Obertöne, die, weil sie proportional $N^{4}$ stärker sind als der Grundton und das menschliche Ohr für sie viel empfindlicher ist, so störend sind, dass für Töne unter $N=200$ nichts zu machen war.

Viel über den ersten Eigenton der Platte hinaus konnte man bei dem Bell'schen Telephon nicht gehen, da dann die Bewegung der Platte eine uncontrolirbare wird. In Folge dessen mussten für die höheren Töne andere Telephone mit kleineren Platten verwandt werden. Für hohe Töne war ihre Tonintensität genügend. Es wurden benutzt für den Tonbereich:

$$
\begin{aligned}
& N=200-1050 \quad \text { Bell' sches Telephon, } R=2 \mathrm{~cm} \\
& \text { Tiefster Eigenton: 945, } \\
& N=420-4000 \quad \text { Telephon III, } R=1 \mathrm{~cm} \\
& \text { Tiefster Eigenton: 5500, } \\
& N=2700-12000 \quad \text { Telephon } \mathrm{V}, R=0,5 \mathrm{~cm} \\
& \text { Tiefster Eigenton ca. } 20000 .
\end{aligned}
$$

Bei den hohen Tönen trat eine andere Schwierigkeit auf, nämlich die Reflexion der Schallwellen an dem Kopfe des Beobachters. Nach Rayleigh ${ }^{1}$ ) ruft ein Gegenstand merkliche Störungen des Schalles hervor, wenn seine Dimensionen von derselben Grössenordnung sind wie die Wellenlänge des Tones. Bei höheren Schwingungszahlen musste daher der Kopf des Hörenden störend wirken.

Um diese Schwierigkeit zu umgehen, wurden Tonquelle und Ohr vertauscht. Dies ist nach dem $\mathrm{Helmhol} \mathrm{tz}$ 'schen Reciprocitätsgesetz erlaubt, dessen Gültigkeit in diesem Fall durch specielle Versuche nachgewiesen wurde (vgl. Anhang I S. 47). Fs wurde also das $\mathrm{Ohr}$ an die Oeffnung des Bleches gebracht und das Telephon in die Entfernung $\varrho$ dem Ohr gegenüber. Die Dimensionen der Telephone waren immer klein gegen die Wellenlänge. Zur sichereren Vermeidung stehender Schwingungen wurde die Platte des Telephons unter $45^{\circ}$ gegen das Blech geneigt (cf. Fig. $7 a$ ).

1) Rayleigh, Theory of sound vol. $2 \S 334$. 
Die Untersuchung wurde bei Nacht im grossen Hörsaal des physikalischen Instituts mit intermittirenden Tönen gemacht, und zwar von zwei bis drei unabhängigen Beobachtern. Die Anordnung der Stromverzweigung war wie oben eingerichtet, nur dass auch im Telephonkreis stets durch Selbstinduction und Capacität Resonanz hervorgerufen wurde, um den Strom noch mehr von seinen Oberströmen zu reinigen.

Es sei hier eine vollständige Versuchsreihe angeführt. $K_{1}$ und $K_{2}, W_{1}$ und $W_{2}$ sind zwei hinter einander gemachte Einstellungen der beiden Beobachter $K$ und $W$, und zwar sind die im Rheostaten des Telephonkreises gezogenen Widerstände im Ohm angegeben. $\beta$ ist der Ausschlag des Dynamometers, $W_{E}$ der Nebenschlusswiderstand zum Telephonkreis (vgl. Fig. 1 S. 8).

Telephon III.

\begin{tabular}{|c|c|c|c|c|c|c|}
\hline$N$ & $K_{1}$ & $K_{2}$ & $W_{1}$ & $W_{2}$ & $\beta$ & $W_{E}$ \\
\hline $\begin{array}{r}2700 \\
4000 \\
6000 \\
8000 \\
12000\end{array}$ & $\begin{array}{r}400 \Omega \\
800 " \\
1000 " \\
2000 " \\
400 "\end{array}$ & $\begin{array}{r}500 \Omega \\
1200 " \\
800 " \\
1000 " \\
400 "\end{array}$ & $\begin{array}{r}500 \Omega \\
500 " \\
3000 " \\
2000 " \\
500 "\end{array}$ & $\begin{array}{r}300 \Omega \\
600 \\
3000 \\
2500 \\
400 "\end{array}$ & $\begin{array}{l}150 \\
220 \\
200 \\
170 \\
1,7\end{array}$ & $\begin{array}{r}40 \Omega \\
40 " \\
40 " \\
40 " \\
100 "\end{array}$ \\
\hline
\end{tabular}

Der übrige Widerstand des Telephonkreises betrug circa $50 \Omega$. 1 Scalentheil des Dynamometers entsprach einer Stromamplitude im Hauptzweig $=2,90 \cdot 10^{-3}$ Ampère. Danach berechnet sich z. B. für $N=2700$ der Mittelwerth für den Beobachter $W\left(\frac{W_{1}+W_{2}}{2}=400\right)$

$$
=2,90 \cdot 10^{-8} \cdot \frac{\sqrt{150} \cdot 40}{400+50+40}=2,9 \cdot 10^{-3} \text {. }
$$

Die obige Versuchsreihe ergibt hiernach:

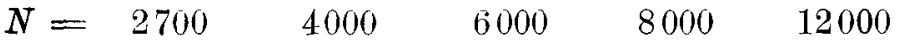

$$
\begin{aligned}
& K=2,6 \cdot 10^{-3} \quad 1,6 \cdot 10^{-3} \quad 1,7 \cdot 10^{-3} \quad 9,5 \cdot 10^{-4} \quad 7,0 \cdot 10^{-4} \text { Ampère. } \\
& W=2,9 \cdot 10^{-3} \quad 2,6 \cdot 10^{-3} \quad 5,3 \cdot 10^{-4} \quad 6,9 \cdot 10^{-4} \quad 6,3 \cdot 10^{-4} \quad \text { ， }
\end{aligned}
$$

Eine zweite Versuchsreihe, die einige Wochen später gemacht wurde, ergab :

$$
\begin{aligned}
& N=\begin{array}{llll}
4000 & 6000 & 8000 & 12000
\end{array} \\
& K=1,9 \cdot 10^{-3} \quad 2,0 \cdot 10^{-3} \quad 7,3 \cdot 10^{-4} \quad 9 \cdot 10^{-4} \text { Ampèrc. } \\
& W^{\prime}=1,5 \cdot 10^{-3} \quad 7,1 \cdot 10^{-4} \quad 5,0 \cdot 10^{-4} \quad 6 \cdot 10^{-4} \quad \text { ， }
\end{aligned}
$$


Die folgende Tabelle gibt das Mittel beider Versuchsreihen für $K$ und $W$ und schliesslich $\alpha_{I I}$, das Gesammtmittel beider Beobachter. $N=\begin{array}{rrrrr}2700 & 4000 & \left.6000^{x}\right) \quad 8000 & 12000\end{array}$ $K=2,6 \cdot 10^{-3} 1,75 \cdot 10^{-3} 1,85 \cdot 10^{-3} 8,4 \cdot 10^{-4} 8,0 \cdot 10^{-4}$ Ampère. $W=2,9 \cdot 10^{-3} \quad 2,05 \cdot 10^{-3} \quad 6,2 \cdot 10^{-4} \quad 6,0 \cdot 10^{-4} \quad 6,2 \cdot 10^{-4} \quad$ n $\alpha_{I I}=2,75 \cdot 10^{-3} 1,90 \cdot 10^{-8} 1,23 \cdot 10^{-3} \quad 7,2 \cdot 10^{-4} 7,1 \cdot 10^{-4} \quad$ "

Um aus dem Strom auf die Tonintensität schliessen zu können, müssen die Excursionen der Mitte der Telephonplatte für einen bestimmten Strom bei den verschiedenen Schwingungszahlen bekannt sein. Für das Bell'sche Telephon, in der Form, wie es zu diesen Versuchen benutzt wurde, sind, wie oben erwähnt, die Excursionen mikroskopisch gemessen. Man kann also die durch den Minimalstrom $\alpha_{I I}$ hervorgerufenen Excursionen berechnen. Die relative logarithmische Empfindlichkeit $E^{\prime}$ ergibt sich hiernach bezogen, auf den tiefsten Ton, zu

$$
E^{\prime}=\lg \frac{a_{t}^{2} N_{t}^{4}}{a_{o}{ }^{2} N^{4}}
$$

worin $a_{t}$ und $N_{t}$ Excursion und Schwingungszahl des tiefsten Tones sind.

Da die Fxcursionen direct gemessen waren, konnte man bei diesem Telephon etwas über den tiefsten Figenton (945) hinausgehen (vgl. S. 14).

Bei den anderen Telephonen waren die Excursionen zu klein, um sie mit dem Mikroskop zu messen. Es konnte daher, wie oben, nur die Correction für die Abnahme der magnetischen Kraftlinie mit der Schwingungszalll eingeführt werden, indem der Strom mit dem Verbältniss der Selbstpotentiale multiplicirt wurde. Demnach ergibt

1) Bei diesen Versuchen über sehr hohc Töne war es auffallend, dass für den Ton 6000 die Empfindlichkeit bei $W^{r}$ viel höher war wie ba $K$. Es ergibt sich das aus den einzelnen Versuchen und wurde auch direct bestätigt, indem $W$. für einen Strom, bei denı $K$. nichts mehr hören konnte, noch einen ziemlich lauten Ton vernahm. Da für die übrigen Töne die Empfindlichkeit Beider etwa die gleiche war, so muss man annehmen, dass der Ton 6000 bei $W$. irgendwie durch Resonanz, vielleicht im Gehörgang, verstärkt wurde.

Bei dem Ton 12000 wurde ein Einfluss der Ohrmuschel von beiden Beobachtern constatirt. Wenn die Ohrmuschel ganz durch das Loch im Blechschirm hindurchgesteckt wurde, erwies sich das Ohr etwa drei Mal so cmpfindlich, wie wenn die Ohrmuschel seitlich gegen den Rand des Bleches gedrïickt wurde. Der Gehörgang war natürich in beiden Fällen völlig frei. Bei tieferen Tönen war kein Unterschied festzustellen. 
sich bei diesen beiden Telephonen die relative logarithmische Empfindlichkeit $E^{\prime}$, bezogen auf den tiefsten Ton, zu $E^{\prime}=\lg \left(\frac{L_{t}^{2} N_{t}^{4}}{\alpha_{I I}{ }^{2} L_{N}^{2} N^{4}}\right)$. Natürlich musste man hier stets unter dem tiefsten Eigenton bleiben, damit die Excursionen der Platte bei gleicher Kraft für alle Schwingungszahlen gleich angenommen werden konnten.

Der Tonbereich der verschiedenen Telephone greift weit über einander. Diese gemeinsamen Werthe kann man dazu benutzen, um die Telephone III und V auf das Telephon I zu beziehen. Dazu muss eine additive Constante zu dem $E^{\prime}$ von Telephon III hinzugefügt werden, so dass die Werthe für $N=420,820,1100$ möglichst sich an die Werthe von $400,600,1050$ des Telephons I anschliessen. Ebenso wurden dann die Werthe des Telephons $\mathrm{V}$ an die des Telephons III angeschlossen. So ergibt sich die gemeinsame logarithmische Empfindlichkeit der drei Telephone $E^{\prime \prime}$, bei Telephon I $=E^{\prime}+0$, bei Telephon III $=E^{\prime}+2,1$, bei Telephon $\mathrm{V}$ $=E^{\prime}+2,9$. Die Tabelle XII gibt nun die Resultate: Unter $F, K, W$ die von den Beobachtern $F, K$ und $W$ gefundenen Minimalströme, $\alpha_{I I}$ der Mittelwerth. $a_{v}$ die Excursion der Mitte der Platte des Telephons I, $L_{N}$ die Selbstinduction der Telephone III und V für die Schwingunঞsszahl $N$. Die logarithmischen Empfindlichkeiten $E^{\prime}$ und $E^{\prime \prime}$ sind soeben besprochen. Ueber $E$ weiter unten.

Tabelle XII.

Telephon I. Tiefster Eigenton 945.

\begin{tabular}{r|c|c|c|c|c|c|c|c}
\hline$N$ & $F$ & $W$ & $\alpha_{I I}$ & $a_{0} / \alpha I I$ & $a_{0}$ & $E^{\prime}$ & $E^{\prime \prime}$ & $E$ \\
\hline 200 & $7,0 \cdot 10^{-3}$ & $5,1 \cdot 10^{-3}$ & $6,05 \cdot 10^{-3}$ & 0,0029 & $1,8 \cdot 10^{-5}$ & 4,43 & 4,43 & 9,83 \\
400 & $1,6 \cdot 10^{-4}$ & $2,2 \cdot 10^{-4}$ & $1,9 \cdot 10^{-4}$ & 0,0031 & $6,0 \cdot 10^{-7}$ & 6,18 & 6,18 & 11,58 \\
600 & $8,0 \cdot 10^{-5}$ & $4,1 \cdot 10^{-5}$ & $6,05 \cdot 10^{-5}$ & 0,0034 & $2,1 \cdot 10^{-7}$ & 6,39 & 6,39 & 11,79 \\
1050 & $4,0 \cdot 10^{-6}$ & $2,1 \cdot 10^{-6}$ & $3,05 \cdot 10^{-6}$ & 0,0053 & $1,6 \cdot 10^{-8}$ & 7,63 & 7,63 & 13,03 \\
& & & & & & & &
\end{tabular}

Telephon III. Tiefster Eigenton ca. 5500.

\begin{tabular}{r|c|c|c|c|c|c|c|c}
\hline \multicolumn{1}{c|}{$N$} & $F$ & $K$ & $W$ & $\alpha_{I I}$ & $L_{N}$ & $E^{\prime}$ & $E^{\prime \prime}$ & $E$ \\
\hline 420 & $6,5 \cdot 10^{-3}$ & $1,3 \cdot 10^{-2}$ & $9,0 \cdot 10^{-3}$ & $9,5 \cdot 10^{-3}$ & $1,2 \cdot 10^{7}$ & 4,04 & 6,14 & 11,54 \\
820 & $6,1 \cdot 10-4$ & $4,3 \cdot 10^{-4}$ & $6,1 \cdot 10^{-4}$ & $5,5 \cdot 10^{-4}$ & $1,1 \cdot 10^{7}$ & 5,31 & 7,41 & 12,81 \\
1100 & $3,7 \cdot 10^{-4}$ & $1,7 \cdot 10^{-4}$ & $2,2 \cdot 10^{-4}$ & $2,5 \cdot 10^{-4}$ & $1,0 \cdot 10^{7}$ & 5,67 & 7,77 & 13,17 \\
2700 & $4,1 \cdot 10^{-5}$ & $5,1 \cdot 10^{-5}$ & $3,9 \cdot 10^{-5}$ & $4,0 \cdot 10^{-5}$ & $8,5 \cdot 10^{6}$ & 5,86 & 7,96 & 13,36 \\
4000 & $2,0 \cdot 10^{-5}$ & $1,7 \cdot 10^{-5}$ & $2,0 \cdot 10^{-5}$ & $1,9 \cdot 10^{-5}$ & $7,5 \cdot 10^{6}$ & 5,93 & 8,03 & 13,43
\end{tabular}


Ueb. die Empindlichkeit des menschl. Ohres für Töne verschied. Höhe.

Telephon V. Tiefster Eigenton ca. 20000.

\begin{tabular}{r|c|c|c|c|c|c|c}
\hline \hline$N$ & $K$ & $W$ & $\alpha_{I I}$ & $L_{N}$ & $E^{\prime}$ & $E^{\prime \prime}$ & $E$ \\
\hline 2700 & $2,60 \cdot 10^{-3}$ & $2,90 \cdot 10^{-3}$ & $2,75 \cdot 10-3$ & $1,45 \cdot 10^{6}$ & 5,12 & 8,02 & 13,42 \\
4000 & $1,75 \cdot 10-3$ & $2,05 \cdot 10^{-3}$ & $1,90 \cdot 10-3$ & $1,35 \cdot 10^{6}$ & 4,82 & 7,72 & 13,12 \\
6000 & $1,85 \cdot 10-3$ & $6,20 \cdot 10-4$ & $1,23 \cdot 10-3$ & $1,25 \cdot 10^{6}$ & 4,56 & 7,46 & 12,86 \\
8000 & $8,40 \cdot 10-4$ & $6,00 \cdot 10-4$ & $7,20 \cdot 10-4$ & $1,20 \cdot 10^{6}$ & 4,56 & 7,46 & 12,86 \\
12000 & $8,00 \cdot 10-4$ & $6,20 \cdot 10^{-4}$ & $7,10 \cdot 10^{-4}$ & $1,10 \cdot 10^{8}$ & 3,95 & 6,85 & 12,25
\end{tabular}

In der Fig. 8 sind die Werthe von $E^{\prime \prime}$ für die drei Telephone aufgetragen und durch Curven verbunden (I); man sieht, dass die drei

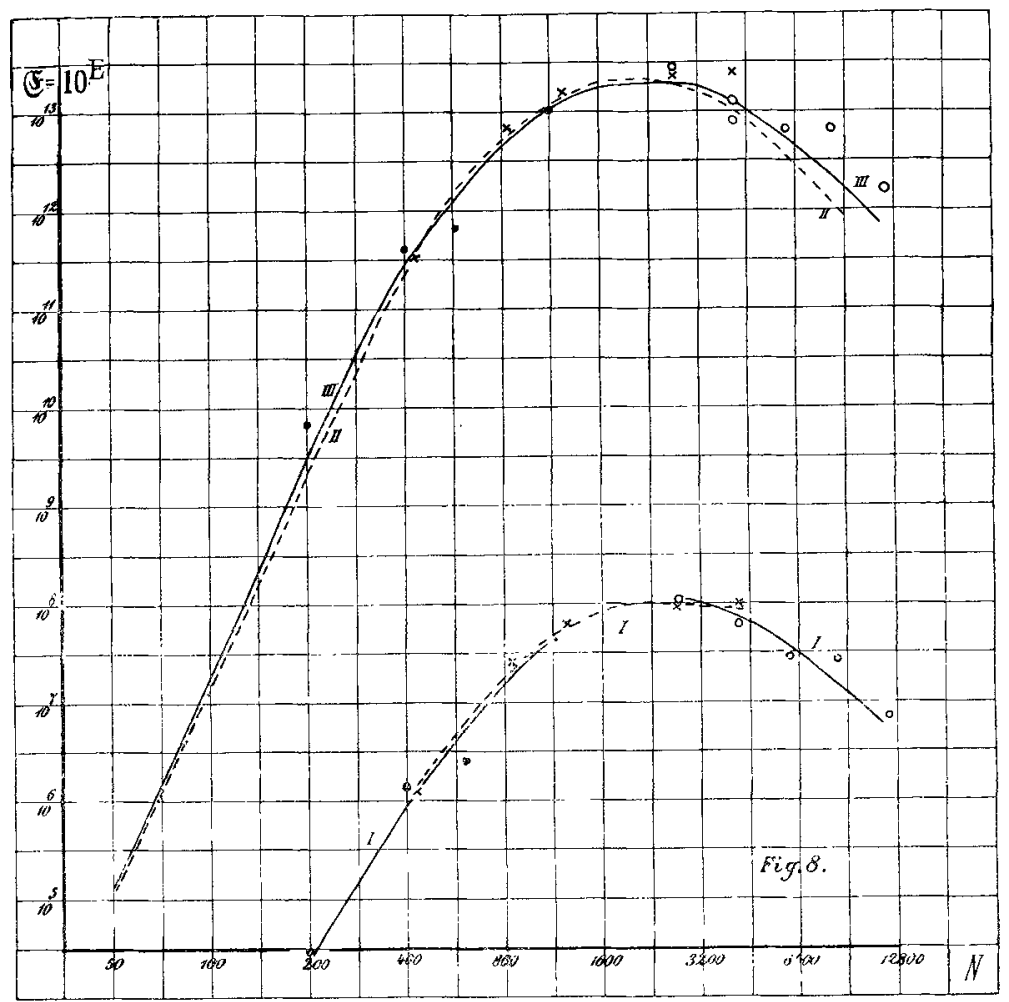

Fig. 8.

Curven gut in einander ubbergehen. Ueber diesen Curven ist noch die punktirte Curve II gezeichnet, welche die Resultate des vorigen Abschnitts, die "Telephonempfindlichkeit" angibt. Offenbar ist der Verlauf sehr ähnlich; das tritt noch deutlicher hervor, wenn man die unteren Curven versehiebt, so dass sie mit der Curve $I I$ zur Deckung 
kommen. Dazu muss wieder eine additive Constante zu $E^{\prime \prime}$ hinzugefügt werden, so dass wir erhalten $E=E^{\prime \prime}+5,4$. Die Werthe von $E$ sind wieder eingetragen. Offenbar liegen sie alle in der Nähe der Curve II. Die Curve III ist nun so gezogen, dass bei ihr die kleinen Abweichungen der neuen Werthe von der Curve II berücksichtigt sind. Curve III ist also nun die

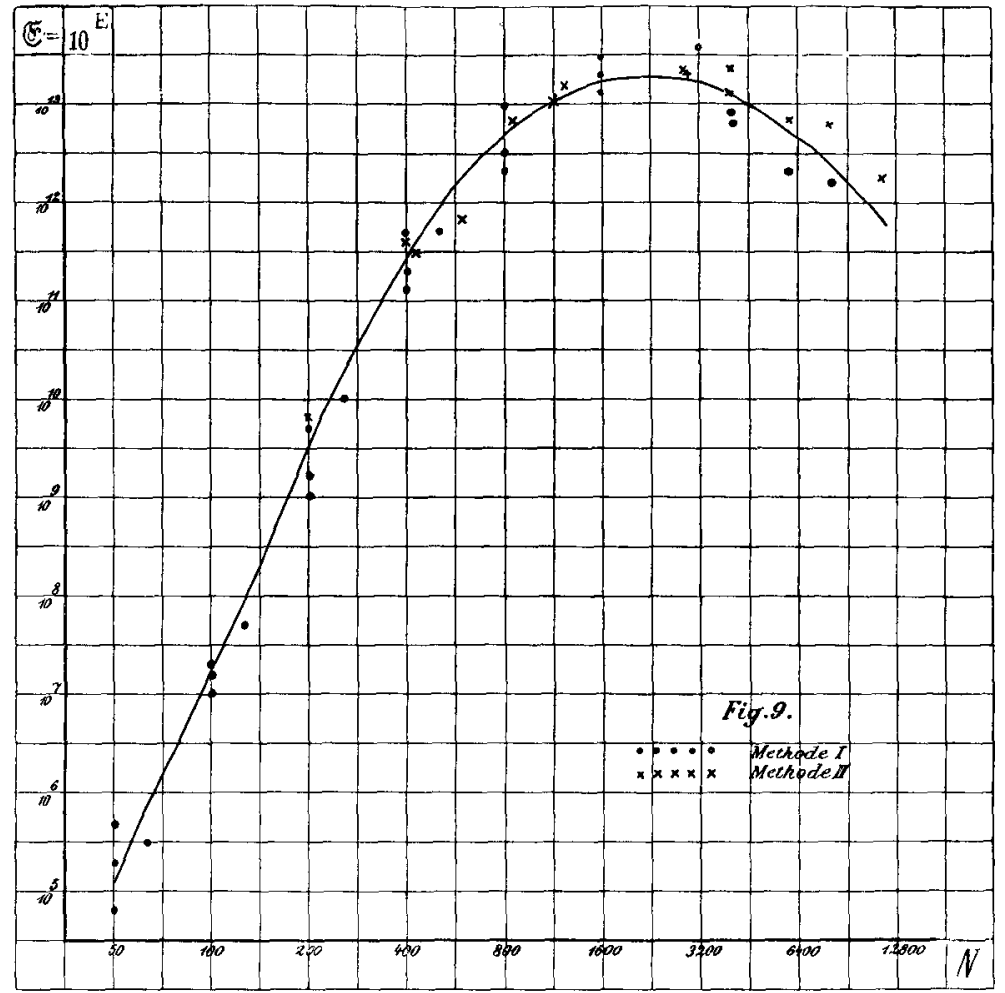

Fig. 9.

definitive Curve, durch die nach sämmtlichen Versuchendie relative Empfindlichkeit normaler Ohren dargestellt wird. In Fig. 9 ist sie nun nochmals angegeben, und ausserdem sind sämmtliche Werthe, aus denen sie abgeleitet ist, eingezeichnet; die der Telephonempfindlichkeit als Punkte, die neuen Werthe als Kreuze. Man sieht, dass wohl hie und da grössere Abweichungen, besonders bei den ganz hohen Tönen, vorkommen, jedoch im Ganzen die Punkte und Kreuze der Curve so nahe liegen, wie man es nur irgend bei den grossen 
Ueb. die Empindlichkeit des menschl. Ohres für Töne verschied. Höhe.

Fehlern der einzelnen Beobachtung und bei der schwierigen Bestimmung der Tonintensität erwarten kann. Allerdings muss dabei berücksichtigt werden, dass es sich immer um den Logarithmus der wahren Empfindlichkeit bei den Curven handelt, dass daher ein Punkt, der um 0,6 uber der Curve liegt, eigentlich den vierfachen Werth der Empfindlichkeit angibt.

Die Art der Tonerzeugung ist hei beiden Methoden möglichst einfach und theoretisch übersichtlich. Grössere principielle Fehler dürften daher, soweit sich das beurtheilen lässt, nicht in den Resultaten vorhanden sein und der Verlauf der relativen Empfindlichkeit mit der Tonhöhe durch die Curve III wenigstens der Grössenordnung nach richtig wiedergegeben sein.

Besprechung der Resultate.

Aus den Tabellen und Curven ergeben sich ganz ausserordentlich grosse Differenzen in der Empfindlichkeit des menschlichen Ohres für Töne verschiedener Höhe. Damit wir einen Ton von 50 Schwingungen eben vernehmen können, muss derselbe eine ca. 100 Millionen Mal so grosse Energie besitzen wie ein Ton von 2000 Schwingungen. Die logarithmische Empfindlichkeit steigt von den tiefsten Tönen annähernd geradlinig bis zu $N=400$ an; darauf wird der Anstieg langsamer. Dieser Theil stimmt also mit der ohen angeführten $\mathrm{H} \mathrm{elm-}$ holtz'schen qualitativen Beobachtung an der Doppelsirene überein. Von 1000 his 5010$)$ liegt ein breites Maximum; darauf beginnt die Empfindlichkeit wieder lanosam zu fallen. Das Maximum der Empfindlichkeit liegt also gerade da, wo die charakteristisehen Töne der menschlichen Sprache sich befinden. Nur auf der ausserordentlich grossen Empfindlichkeit für diese äusserst schwachen und schnell abklingenden charakteristischen Töne beruht die Möglichkeit des Verständnisses der Sprache unter ungünstigen Bedingungen: auf grosse Entfernung hin, oder bei sehr viel stärkeren Nebengeräuschell, wie beim Brausen des Meeres, oder auch bei der sehr unvollkommenen telephonischen Uehertragung.

Wenn ein Extrapoliren ausserhalb der untersuchten Schwingungszahlen gestattet ist, so ist der Verlauf der Empfindlichkeitscurve derartig, dass der Abfall nach den tiefen Tönen noch ein Stück in derselben Weise weiter gehen dürfte. Dann wäre die Schwellenenergie für die Schwingungszahl 12,5 wieder etwa 1000 Mal grösser wie die bei $N=50$. Ob wir solche Schwingungen noch als Töne 
wahrnehmen könnten, wenn sie ganz rein sinusförmig unser Ohr träfen, ist natürlich sehr schwer zu sagen. Die Excursionen des Schwellentones sind schon recht erheblich, und auf solche starken Excursionen sind die Apparate der Paukenhöhle nicht eingerichtet.

Bei den hohen Schwingungszahlen haben wir kaum das Gebiet des steileren Abfalls der Empfindlichkeit erreicht. Dieser dürfte erst etwa bei 20000 für normale Ohren liegen.

Jedenfalls ergeben die Versuche, dass die Hörgrenzen, wie schon am Eingang ausgesprochen, davon abhängig sind, wie starke reine Töne man zu erzeugen im Stande ist, je höher die Tonstärke, um so grösser ist der Tonbereich. In der Tiefe ist es jedoch schwer, die Obertöne zu vermeiden. In der Höhe kann man nur schwer grössere Intensitäten erzielen, auch stören oft zischende und andere Nebengeräusche. Wie wir unten sehen werden, liegt die Schwellenenergie für $N=50$ bei ca. $3 \cdot 10^{-4}$ Erg. Gelänge es aus irgend einem Grunde nicht, stärkere Töne als von $10^{-10} \mathrm{Erg}$ an unser Ohr gelangen zu lassen, so würde die untere Hörgrenze bei $N=500$, die obere bei $N=$ ca. 13000 liegen. Wäre nur eine Intensität von $5 \cdot 10^{-12}$ erreichbar, so würde unser Hörgebiet sich nur von 1000 bis 4000 erstrecken.

Für die grossen Differenzen in der Empfindlichkeit eine Erklärung zu finden, ist vorläufig wohl nicht möglich. Rein mechanisch-physikalische Dinge genügen nicht dazu: weder die Beobachtung von Politzer1), dass die Gehörknöchelchen in der Mittellage intensiver mitschwingen als bei den ganz tiefen und ganz hohen Tönen, noch auch die Helmholtz'sche Resonanztheorie.

Helmholtz selbst hat aus Trillerversuchen auf eine ziemlich starke Dämpfung der mitschwingenden Theile im Ohr geschlossen. Mit starker Dämpfung ist aber eine ausgesprochene Resonanz nicht vereinbar. Durch stärkeres Mitschwingen der resonirenden Theile der Schnecke könnte vielleicht eine tausendfache Empfindlichkeit erklärt werden, nicht aber eine 100-Millionenfache.

Nehmen wir an, es mache der Theil der Membrana basilaris, welcher auf einen Ton von 2000 Schwingungen reagirt, für diesen eine 100 Mal grössere Excursion wie für einen genügend entfernten tieferen Ton, z. B. von 50 Schwingungen. Die Reizschwelle für den Ton 2000 liegt nun andererseits über 100 Millionen Mal tiefer wie die für den

1) Tröltsch's Arch. Bd. 6 S. 35. 1871. 
Ton 50, die entsprechenden Druckdifferenzen sind also bei dem Ton 50 mehr als 10000 Mal grösser. Auf diese Druckdifferenzen muss der Theil der Membran, der den Eigenton 2000 besitzt, ebenfalls erzwungen mitschwingen, und zwar können die Excursionen $\frac{10000}{100}=100$ Mal grösser sein als bei dem Schwellentone von $N=2000$, ohne dass eine Tonempfindung zu Stande käme.

Um dies zu erklären, müssten wir annehmen, dass die Schwingungen der einzelnen Theile der Membran nur dann von einer Empfindung begleitet sind, wenn sie gerade in der Periode ihres Figentons schwingen. Auch viel stärkere Schwingungen von fremder Periode werden nicht an die Nerven oder an das Centralorgan weitergegeben. Damit ertheilen wir aber diesen Organen "specifische Energie“ und schieben auf sie die Aufgabe ab, welche nach der Helmholtz'schen Theorie eigentlich durch die Resonanz in der Schnecke geleistet werden sollte, geben also zu, dass die Resonanztheorie zur Erklärung der Erscheinung nicht ausreicht. Der Schnecke bleibt nur die Rolle eines Empfangs- oder Uebertragungsapparats, der vielleicht eine vorläufige Auslese trifft, die Hauptaufgabe wird jedoch anderswo gelöst.

\section{Absolute Empfindlichkeit.}

Aus den im Anhang I gegebenen Formeln kamn, wenn die Bewegung der Platte gegeben ist, die Tonintensität für irgend einen entfernten Punkt in absolutem Maass berechuet werden. Die Excursionen der Platte des Telephons I sind, wie oben S. 14 besprochen, mikroskopisch für verschiedene Schwingungszahlen gemessen; demnach kann die Fnergie, die unser Ohr trifft, in Centimetern, Gramm, Sekunden und damit die absolute Empindlichkeit des menschlichen Ohres für Töne verschiedener Höhe angegeben werden. In der Tabelle XIII ist für die Versuche mit Telephon I diese Berechnung durchgeführt. Zunächst sind wieder die Minimalströme $\left(\alpha_{I I}\right)$ angegeben, dann die Excursionen der Platte für eine Stromamplitude von 1 Ampère $\left(a_{o} / \alpha_{I I}\right)$, darauf die relative Druckdifferenz: $\mathcal{I}=0,147 \cdot \frac{k}{c^{2}} \frac{(2 \pi N)^{2} a_{o}}{\varrho} R^{2}$, die dieser Druckdifferenz entsprechende Geschwindigkeit der Lufttheilchen bei ebenen Wellen $u=\frac{c d}{h}$, die Amplitude bei ebenen Wellen $\xi=\frac{u}{2 \pi N}$ und schliesslich die Energie 
in Erg, welche durch 1 qcm senkrecht zur Schallrichtung pro Secunde hindurchtritt: $A=1,19 \cdot 10^{10} \Delta^{2}$ Erg.

Tabelle XIII. Telephon I.

\begin{tabular}{|c|c|c|c|c|}
\hline$N$ & $\alpha_{I I}$ (Amp. & $\alpha_{0} / \alpha_{I I}$ & $\sigma_{0}(\mathrm{~cm})$ & $\Delta$ \\
\hline $\begin{array}{r}200 \\
400 \\
600 \\
1050\end{array}$ & $\begin{array}{l}6,05 \cdot 10-3 \\
1,9 \cdot 10-4 \\
6,05 \cdot 10-5 \\
3,05 \cdot 10-6\end{array}$ & $\begin{array}{l}0,0029 \\
0,0031 \\
0,0034 \\
00,053\end{array}$ & $\begin{array}{l}1,8 \cdot 10-5 \\
6,0 \cdot 10-7 \\
2,1 \cdot 10-7 \\
1,6 \cdot 10-8\end{array}$ & $\begin{array}{l}7,0 \cdot 10^{-10} \\
9,4 \cdot 10^{-11} \\
7,4 \cdot 10^{-11} \\
1,7 \cdot 10^{-11}\end{array}$ \\
\hline$N$ & $u$ & & $\xi(\mathrm{cm})$ & $A$ (Erg) \\
\hline $\begin{array}{r}200 \\
400 \\
600 \\
1050\end{array}$ & $\begin{array}{l}1,7 \\
2,3 \\
1,8 \\
4,1\end{array}$ & & $\begin{array}{l}1,3 \cdot 10^{-8} \\
9,0 \cdot 10^{-10} \\
4,6 \cdot 10^{-10} \\
6,3 \cdot 10^{-11}\end{array}$ & $\begin{array}{l}5,8 \cdot 10-9 \\
1,05 \cdot 10-10 \\
6,6 \cdot 10-11 \\
3,5 \cdot 10-12\end{array}$ \\
\hline
\end{tabular}

An der Hand der Curve der Fig. 9 S. 28, welche das Resultat aller Beobachtungen für die relative Empfindlichkeit wiedergibt, kann man die soeben am Telephon I für einen Theil der Curve direct gemessene absolute Empfindlichkeit auf den ganzen Tonbereich ausdehnen. Dies geschah, indem zunächst an der Curve selbst für die verschiedenen Schwingungszahlen die logarithmische Empfindlichkeit $E$ durch Ausmessen bestimmt wurde; dadurch fielen die zufälligen Beobachtungsfehler heraus. Dann wurde daraus rückwärts die Schwellenenergie berechnet und hieraus $A, u$ und $\xi$. $A$ ist sowohl in Erg als auch in $\mu \mu \mathrm{mg}$ angegeben. $A^{\prime}$ ist diejenige Energie, welche auf das Trommelfell treffen muss, um gerade noch eine Tonempfindung $\mathrm{zu}$ erregen, wobei das Trommelfell $\mathrm{zu} 1 / 3 \mathrm{qcm}$ gerechnet, und nach dem Vorgange von $Z$ wardemaker und $\mathrm{Qu}$ ix die Anzahl der Schwingungen, welche nothwendig ist, um eine Tonempfindung zu erregen, bis zur Schwingungszahl $3500 \mathrm{zu} 2$, bei $6400 \mathrm{zu} 7$ und bei $12800 \mathrm{zu} 20$ angenommen ist.

1) In dem Bericht über meinen Vortrag auf der Karlsbader NaturforscherVersammlung (Physik. Zeitschr. Bd. 4 S. 69. 1902. Verhandl. d. Deutsch. physik. Gesellsch. Bd. 4 S. 297. 1902) ist durch einen Rechenfehler $u$ etwa zehn Mal zu gross ausgefallen. 
Ueb. die Empfindlichkeit des menschl. Ohres für Töne verschied. Höhe.

Tabelle XIV.

\begin{tabular}{|c|c|c|c|c|c|c|c|}
\hline \multirow{2}{*}{$N$} & \multirow{2}{*}{$E$} & \multirow{2}{*}{1} & \multirow{2}{*}{$u$} & & \multicolumn{2}{|c|}{$A$} & \multirow{2}{*}{$A^{\prime}$ Erg } \\
\hline & & & & & Erg & $\mu \mu \mathrm{mg}$ & \\
\hline 50 & 5,1 & $1,6 \cdot 10^{-7}$ & $3,9 \cdot 10^{-3}$ & $1,2 \cdot 10^{-5}$ & $3,2 \cdot 10-4$ & 3300 & $4 \cdot 10-6$ \\
\hline 100 & 7,2 & $1,1 \cdot 10^{-9}$ & $2,7 \cdot 10^{-4}$ & $4,2 \cdot 10$ & $1,4 \cdot 10^{-6}$ & 14 & $7 \cdot 10-9$ \\
\hline 200 & 9,5 & $1,0 \cdot 10^{-9}$ & $2,4 \cdot 10-5$ & $1,9 \cdot 10-8$ & $1,2 \cdot 10-8$ & $1,2 \cdot 10-1$ & $3 \cdot 10-11$ \\
\hline 400 & 11,4 & $1,2 \cdot 10^{-10}$ & $2,9 \cdot 10-6$ & $1,1 \cdot 10^{-9}$ & $1,6 \cdot 10-10$ & $1,6 \cdot 10^{-3}$ & $10-13$ \\
\hline 800 & 12,7 & $0^{-11}$ & $5,6 \cdot 10^{-7}$ & $1,1 \cdot 10-10$ & $|8,0 \cdot 10-12|$ & $8,2 \cdot 10-5$ & $7 \cdot 10-15$ \\
\hline 1600 & 13,2 & $1,4 \cdot 10^{-11}$ & $3,4 \cdot 10^{-7}$ & $3,4 \cdot 10-11$ & $2,5 \cdot 10^{-12}$ & $2,5 \cdot 10^{-5}$ & $1 \cdot 10-15$ \\
\hline 3200 & 13 & $1,4 \cdot 10^{-11}$ & $3,4 \cdot 10^{-7}$ & $1,7 \cdot 10^{-11}$ & $2,5 \cdot 10-12$ & $2,5 \cdot 10-5$ & $5 \cdot 10-16$ \\
\hline 6400 & 12 & $2,3 \cdot 10$ & $5,6 \cdot 10^{-7}$ & $1,4 \cdot 10^{-11}$ & $8,0 \cdot 10^{-12}$ & $8,2 \cdot 10^{-5}$ & $3 \cdot 10-15$ \\
\hline 1280 & 11,6 & $8,0 \cdot 10^{-11}$ & $1,9 \cdot 10^{-6}$ & $2,4 \cdot 10^{-11}$ & $9,0 \cdot 10-11$ & $9,2 \cdot 10^{-4}$ & $5 \cdot 10-14$ \\
\hline
\end{tabular}

Die in dieser Weise gefundenen absoluten Werthe der Reizschwellen sind etwas kleiner, als sie sich bei früheren Einzelversuchen ergeben hatten. So bestimmte Rayleigh ${ }^{1}$ ) mit Hülfe abklingender Stimmgabeln für

$$
\begin{aligned}
& N=256 \quad 384 \quad 512 \\
& \Delta=8,5 \cdot 10^{-9} \quad 6 \cdot 10^{-9} \quad 6 \cdot 10^{-9}
\end{aligned}
$$

Mittelst Hel in holtz'scher Resonatoren fand ich auf durchaus andere Art in einer früheren Arbeit $^{2}$ ) für $N=440,1=8 \cdot 10^{-10}$. Es mag diese Differenz zum Theil an den günstigeren Bedingungen liegen, unter denen ich diesmal arbeitete (beinahe völlige Stille, intermittirende Töne, u. s. w.). Auf der anderen Seite ist es jedoch sehr auffallend, dass R a y leig $h$ bei seinem Stinmgabelversuche keinen merklichen Unterschied zwischen der Empfindlichkeit für $N=256$ und $N=512$ feststellen konnte, während er selbst bei Telephonversuchen genau entsprechend meinen Resultaten eine mit der Schwingungszahl stark steigende Empfindlichkeit fand:

$$
N=128192 \quad 256307320 \text { 384 512 } 640 \quad 768
$$

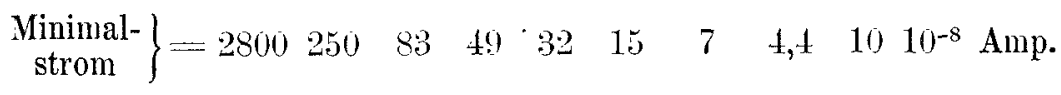

Rayleigh sucht den Grund der Differenz in dem Eigenton der Platte des Telephons. Jedoch dürfte diese Erklärung kaum ausreichen, um das gleichmässige Ansteigen bis $N=512$ zu erklären, besonders da der Eigenton seiner Telephonplatte der Berechnung: nach erst bei 541 , dem Versuch nach sogar erst bei $N=896$ lag. Bei meinen Versuchen ist diese Fehlerquelle ja principiell umgangen.

1) Rayleigh, Phil. Mag. vol. 10 (38) p. 370. 1894.

2) M. Wien, Dissert. S. 46. Wi ed emann's Annalen Bd. 36 S. 849.1889.

E. Pflüg er, Archiv für Phrsiologie. Bd. 97. 
Es ist zu vermuthen, dass die Voraussetzung Rayleigh's, dass bei seinen Versuchen sämmtliche von der Stimmgabel an den Resonator abgegebene Energie in Tonenergie umgewandelt wird, nicht zutrifft, sondern dass durch Reibung und Erschütterung der Wände des Resonators ein mit der Schwingungszahl wachsender Energieverlust eintritt. Rayleigh weist selbst auf diese Fehlerquelle bei seiner Berechnung hin.

Die Tabelle ergiebt ganz ausserordentlich geringe Energiemengen für die Reizschwelle. Besonders $A^{\prime}$, welches von $\mathrm{Z}$ wardemaker und Quix als das eigentliche Maass der Reizschwelle angesehen wird, zeigt uns zwischen den Schwingungszahlen 800 und 6400 eine staunenswerthe Empfindlichkeit unseres Ohres an, die weder von unserem Auge noch von irgend einem Messinstrument auch nur annähernd erreicht werden dürfte.

\section{Normale und kranke 0hren.}

Zum Schluss sei noch mit wenigen Worten auf die Verwendung der Telephonmethode zu Gehörprüfungen hingewiesen.

Das Princip ist sehr einfach: bei ein und demselben Ton ist die Tonamplitude proportional der Plattenamplitude und diese proportional der Stromintensität. Man kann also direct die Empfindlichkeit eines normalen und kranken Gehörs mit einander vergleichen, indem man das Verhältniss der eben noch hörbaren Stromintensitäten für beide misst. Als Maass der Schwerhörigkeit dient das Verhältniss der Schwellenenergie des kranken Ohres zu der eines normalen Ohres.

Die Methode hat den Nachtheil, dass ein ziemlich complicirter Apparat ${ }^{1}$ ) dazu nothwendig ist, dessen Handhabung von dem Untersuchenden erst erlernt werden muss, den Vortheil, dass das Verhältniss der Schwellenamplituden direct abgelesen wird, Fehler in der physikalischen Bestimmung der Intensität daher so gut wie ausgeschlossen sind.

Da der Gegenstand eigentlich mehr in das Gebiet der Ohrenheilkunde schlägt, so wurden nur einige orientirende Versuche gemacht, um die Brauchbarkeit der Methode darzuthun.

1) Ich bin mit einer Fabrik physikalischer Apparate in Verbindurg getreten, um, falls ein Bedürfniss dafür vorliegt, die ganze Einrichtung der Tonerzeugung in einfacherer und bequemerer fiorm herstellen zu lassen. 
Ueb. die Empfindlichkeit des menschl. Ohres für Töne verschied. Höhe.

Die Empfindlichkeit für tiefere und mittlere Töne liegt bei einigermaassen normal en Ohren auffallend nahe bei einander. Erst bei höheren Tönen ( $N=4000$ und dariber) werden die Abweichungen grösser. Ich verweise zunächst auf die obigen Beobachtungsreihen nach Methode II (S. 25), bei denen stets mehrere Personen als Beobachter dienten. Die Differenzen zwischen den einzelnen Beobachtern liegen in denselben Grenzen wie die bei verschiedenen Versuchen eines Beobachters. Vereinzelte Ausnahmen baben besondere Ursachen, die an der betreffenden Stelle besprochen sind.

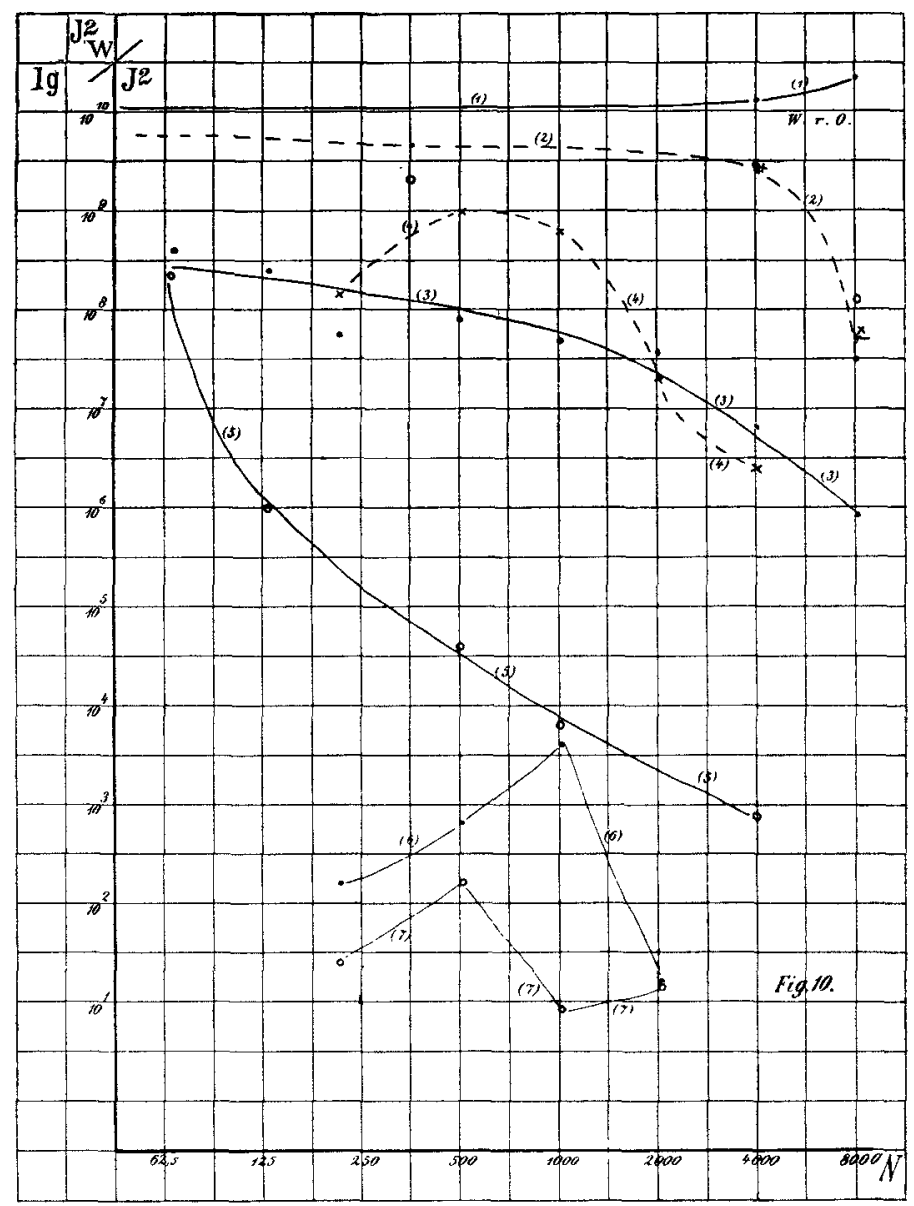

Fig. 10.

Die folgenden Beobachtungen mögen das Gesagte weiter erläutern. Von den untersuchten Personen waren drei (R., V., O.) 
Studirende unserer Hochschule und standen im Alter zwischen 20 und 23 Jahren; F. war 56 Jahre alt. 0 . gab mir an, dass er als Kind an Schwerhörigkeit gelitten hätte. Die Empfindlichkeit der einzelnen Personen wurde direct mit der meines rechten Ohres (W. r. 0.) verglichen, indem ich jedes Mal unmittelbar nach dem Beobachter selbst einstellte. In der Tabelle XV sind die Resultate angegeben. Darin bedeutet $J$ den Minimalstrom für die betreffenden Beobachter, $J_{v}$ den Minimalstrom für mein rechtes $\mathrm{Ohr}, J^{2} / J^{2}{ }_{w}$ mithin das Verhältniss der Schwellenenergie des zu untersuchenden Ohres zu meinem rechten Ohr. Ferner ist $\lg \frac{J_{u^{2}}{ }^{2}}{J^{2}}$ angegeben, also der Logarithmus des Empfindlichkeitsverhältnisses. Diese Grösse ist auch in der Fig. 10 graphisch dargestellt.

In der Fig. 10 ist unter $10^{10}$ die Empindlichkeit meines rechten Ohres als gerade Linie parallel der Abscissenachse eingetragen; auf diese sind alle übrigen Werthe bezogen. Die Curve (1) - gibt die Empfindlichkeit für das empfindlichste, (2) .... für das unempfindlichste unter den "normalen" Ohren an. V. und 0 . sind nur als $O$ bezw. $\times$ eingetragen.

Tabelle XV.

Empfindlichkeit normaler Ohren.

\begin{tabular}{|c|c|c|c|c|c|c|}
\hline \multirow[t]{2}{*}{$N=$} & \multicolumn{2}{|c|}{400} & \multicolumn{2}{|c|}{4000} & \multicolumn{2}{|c|}{8000} \\
\hline & $J^{2} / J_{t t^{2}}$ & $\lg \left(\frac{J_{u t^{2}}}{J^{2}}\right)$ & $J^{2} / J_{m m^{2}}^{2}$ & $\lg \left(\frac{J_{t c^{2}}}{J^{2}}\right)$ & $J^{\mathscr{2}} / J_{v^{2}}$ & $\lg \left(\frac{J_{w^{2}}}{J^{2}}\right)$ \\
\hline $\begin{array}{l}R(1) \\
W \\
V \\
O \\
F(2)\end{array}$ & $\begin{array}{r}1,0 \\
1,0 \\
5,0 \\
1,0 \\
2,25\end{array}$ & $\begin{array}{r}0 \\
0 \\
-0,70 \\
0 \\
-0,35\end{array}$ & $\begin{array}{l}0,8 \\
1,0 \\
4,0 \\
3,8 \\
4,0\end{array}$ & $\begin{array}{c}+0,1 \\
0 \\
-0,6 \\
-0,58 \\
-0,6\end{array}$ & $\begin{array}{c}0,47 \\
1,0 \\
81 \\
209 \\
324\end{array}$ & $\begin{array}{c}+0,33 \\
0 \\
-1,9 \\
-2,3 \\
-2,5\end{array}$ \\
\hline
\end{tabular}

Offenbar ist die Empfindlichkeit erst über der Schwingungszahl 4000 merklich verschieden; bei $N=8000$ wurden die Differenzen besonders bei dem ältesten Beobachter F. schon recht erheblich. Der Abfall der Empfindlichkeit, der bei den normalen Ohren jüngerer Individuen erst bei ca. 15000 Schwingungen beginnt, rückt bei älteren Personen nach den tieferen Tönen hin, - eine Erscheinung, die ja allgemein bekannt ist. Eigenthümlicher Weise scheint nun diese Grenze des steileren Abfalls bei ein und derselben Person nicht ganz 
Ueb. die Empfindlichkeit des menschl. Ohres für Töne verschied. Höhe.

fest zu liegen, sondern ist bald etwas höher, bald tiefer. Bei F. trat z. B. die Unempfindlichkeit ein Mal schon bei $N=3000$ ein, einige Wochen darauf erst bei $N=8000$. Ein Taubstummenlehrer theilte mir mit, dass auch bei seinen Zöglingen Perioden besseren und schlechteren Hörens mit einander abwechselten.

Wesentlich anders verhalten sich erkrankte Ohren. Ich war zufällig in der Lage, an mir selbst Untersuchungen anstellen zu können, indem ich im Juni und Juli 1902 an einem acuten Mittelohrcatarrh des linken Ohres litt. Die Resultate sind unter $W . l .0$. in der Tabelle XVI und unter (3) in der Fig. 10 angegeben. Die Differenzen mit der Empfindlichkeit meines rechten Ohres sind hier schon recht gross: das Verhältniss sinkt von 25 bei $N=64$ bis 13225 bei $N=8000$.

Ich glaubte damals auf dem linken Ohr recht schwerhörig zu sein. Der nächste Beobachter ( $B$ der Tabelle und (4) der Fig. 10), dessen Zahlen und Empfindlichkeitscurve denen meines erkrankten linken Ohres nahe stehen, wusste überhaupt nichts davon, dass er unternormal hörte. Auffallender Weise war dies ein Taubstummenlehrer. Die mitgetheilten Zahlen beziehen sich auf sein rechtes Ohr; auf dem linken hörte er noch schlechter.

Die nächsten Reihen der Tab. XVI $(A)$ und Curve 5 der Fig. 10 gelten für einen wirklich Schwerhörigen. Hier liegt die Reizschwelle schon ca. eine Million $(N=2000)$ und sogar zehn Millionen (4000) Mal höher wie bei einem normalen Ohr. Den Ton 8000 konnte A.

Tabelle XVI.

Verschiedene Grade von Tauhheit.

\begin{tabular}{|c|c|c|c|c|c|c|c|c|}
\hline$N=$ & 64 & 128 & 200 & 500 & 1600 & 2000 & 4000 & 8000 \\
\hline W. l. O. (3) $\left\{\begin{array}{l}J^{y} / l_{l r^{2}} \\
\lg =-\end{array}\right.$ & $\begin{array}{c}25 \\
1,4\end{array}$ & $\begin{array}{c}56 \\
1,6\end{array}$ & 22,5 & $\begin{array}{c}121 \\
2,1\end{array}$ & $\begin{array}{l}225 \\
2,3\end{array}$ & $\begin{array}{r}256 \\
2,4\end{array}$ & $\begin{array}{c}1681 \\
:, 2\end{array}$ & $\begin{array}{c}13225 \\
4,1\end{array}$ \\
\hline$\left\{\begin{array}{l}J^{2} / J_{r^{2}} \\
\lg =-\end{array}\right.$ & - & - & $\begin{array}{l}70 \\
1,8\end{array}$ & $\begin{array}{c}11 \\
1,0\end{array}$ & $\begin{array}{l}16 \\
1,2\end{array}$ & $\begin{array}{c}500 \\
2,7\end{array}$ & $\begin{array}{c}4000 \\
3,6\end{array}$ & $\dot{-}$ \\
\hline$\left\{\begin{array}{l}J^{2} / J_{u^{2}} \\
l g=-\end{array}\right.$ & $\begin{array}{c}43 \\
1,6\end{array}$ & $\begin{array}{c}10^{4} \\
4,0\end{array}$ & - & $\begin{array}{c}6,7 \cdot 10^{5} \\
5,4\end{array}$ & $\begin{array}{c}1,7 \cdot 10^{6} \\
6,2\end{array}$ & - & $\begin{array}{r}1,2 \cdot 10^{7} \\
7,1\end{array}$ & - \\
\hline$K \cdot \sigma \cdot O \cdot(6)\left\{\begin{array}{l}J 2 / J_{1}^{2} \\
l g=\end{array}\right.$ & $\underline{-}$ & -1 & $\begin{array}{l}6,4 \cdot 10^{7} \\
7,8\end{array}$ & $\begin{array}{c}1,6 \cdot 10^{7} \\
7,2\end{array}$ & $\begin{array}{c}2,5 \cdot 10^{6} \\
6,4\end{array}$ & $\begin{array}{r}7 \cdot 10^{8} \\
8,8\end{array}$ & $\overline{-}$ & - \\
\hline K. l. O. (7) $\left\{\begin{array}{l}J^{2} / J_{m^{2}} \\
l g=-\end{array}\right.$ & - & - & $\begin{array}{l}4 \cdot 10^{8} \\
8,6\end{array}$ & $\begin{array}{c}6,4 \cdot 10^{7} \\
7,7\end{array}$ & $\begin{array}{c}1,2 \cdot 10^{9} \\
9,1\end{array}$ & $7 \cdot 10^{8}$ & $\overline{-}$ & $\overline{-}$ \\
\hline
\end{tabular}


auch bei der höchsten mir zur Verfügung stehenden Intensität nicht vernehmen. Immerhin verstand er noch lautes Sprechen in der Nähe ganz gut, war also nicht zu den "Tauben" zu rechnen.

Schliesslich wurden auch noch eine Anzahl taubstummer Kinder untersucht, Zöglinge der hiesigen Provinzial-Taubstummen-Anstalt. Sowohl dem Leiter dieser Anstalt, Herrn Schulrath Linnartz, als auch den Herren Lehrern möchte ich für ihr ungemein freundliches Entgegenkommen auch an dieser Stelle meinen herzlichsten Dank aussprechen.

Es seien hier die Resultate der Beobachtung für einen intelligenten Knaben, der nach Aussage seiner Lehrer besonders grosse Gehörreste besass, angeführt. Im Gegensatz zu den meisten anderen Kindern konnte er mit auffallender Sicherheit die Reizschwelle angeben. Die Tabelle und die Curven (6) und (7) zeigen, dass die "grossen Gehörreste" darin bestanden, dass sein rechtes Ohr nur eine Hörinsel in der Umgebung von $N=1000$ besass; und auch hier war die Empfindlichkeit noch etwa zehn Millionen Mal kleiner als die eines normalen Ohres. Auf dem linken Obr hörte er noch wesentlich schlechter.

Bei den meisten Curven ist hervortretend, dass die hohen Töne relativ viel schlechter von erkrankten Ohren gehört werden als die tiefen. Ich konnte deutlich die Aenderung der Klangfarbe obertonreicher Geräusche, wie Klirren u. s. w., erkennen, je nachdem ich sie mit dem rechten oder dem erkrankten linken Ohr verfolgte. Bei letzterem erschien die Färbung dunkler, weil die hohen Obertöne schwächer bezw. gar nicht mitgehört wurden.

Herr Prof. K ümmel-Heidelberg, dem ich für seinen mehrfachen freundlichen Rath in diesen Fragen Dank schulde, theilte mir mit, dass dies Resultat mit der Beobachtung der Obrenärzte im Widerspruch zu stehen schiene, da diese gefunden bätten, dass der Regel nach bei den Schwerhörigen zunächst neben den ganz hohen auch die ganz tiefen Octaven fortfielen. In den mittleren Octaven sei meist die Hörschärfe noch relativ am grössten. Wie ich sogleich besprechen werde, ist dies Resultat durch die Art und Weise der ohrenärztlichen Untersuchung hervorgerufen, welche nicht ganz einwandsfrei sein dürfte.

Die „Flüstersprache" und ähnliche Methoden kommen hier nicht in Betracht, weil sie nur eine qualitative Untersuchung gestatten. Die „Entfernung der Tonquelle von dem Hörenden" ist ebenfalls 
äusserst unsicher, da man im Zimmer und bei ausgedehnter Tonquelle nichts über die Abnahme der Schallintensität mit der Entfernung sagen kann (vgl. Anhang II).

Es bleibt mithin nur noch die Hartmann-Bezold'sche Stimmgabelmethode übrig. Wie aus der Arbeit von Schwendt und Wagne ${ }^{1}$ ) hervorgeht, scheint man über diese Methode auch nicht ganz im Reinen zu sein, obgleich hier die physikalischen Principien völlig klar liegen.

Die Tonintensität einer Stimmgabel ist unter gleichen Umständen proportional dem Quadrat ihrer Amplitude ${ }^{2}$ ). Liegt die Schwelle für ein normales Ohr bei der Amplitude $a_{n}$, die des kranken Ohres bei $a_{k}$, so ist die Empfindlichkeit umgekehrt proportional der Tonenergie der Schallwellen, also die des normalen Ohres $a^{2}{ }_{k} / a^{2}{ }_{n}$ Mal so gross wie die des kranken. Dieses Verhältniss sollte eigentlich bestimmt werden. Statt dessen wird bei der genannten Methode die Hörd a u er bei möglichst gleichem Anschlagen für das normale $\left(t_{n}\right)$ und für das kranke Ohr $\left(t_{k}\right)$ gemessen, und das Verhältniss der Hördauer $\left(t_{k} / t_{n}=m\right)$ als „Hörschärfe" definirt. Diese Grösse steht jedoch nicht in einem directen Zusammenhang mit dem gesuchten Empfindli chkeitsverhältniss $a_{n}{ }^{2} / a_{k}{ }^{2}$.

Das Abschwingen einer Stimngabel erfolgt nach dem Gesetz $a_{0} e^{-h t}$. Nach der Zeit (Hördauer) $t_{k}$ vernimmt das kranke Ohr ihren Ton nicht mehr; die Amplitude ist dann $a_{k}=a_{0} e^{-7 t_{k}}$. Das normale Ohr erreicht die Schwelle nach der Zeit $t_{n}$

$$
\begin{gathered}
a_{n}=a_{0} e^{-h t_{n}} \\
\frac{a_{n}^{2}}{a_{k}^{2}}=\frac{e^{-2 h t_{n}}}{e^{-2 h t_{k}}}=e^{-2 h\left(t_{n}-t_{k}\right)}=e^{-2 h t_{n}(1-m)}=\left(\frac{a_{n}}{a_{0}}\right)^{2(1-m)} .
\end{gathered}
$$

Das Empfindlichkeitsverhältniss $a_{n}^{2} / a_{l}^{2}$ hängt also ausser von $m$ auch noch von $a_{n} / a_{0}$ ab. Nur in dem Fall würde $m$ ein Maass für die Empfindlichkeit sein können, wenn $a_{n} / a_{0}$ für alle Stimmgaheln unter allen Umständen denselben Werth hätte. Dies ist aber durchaus nicht der Fall. Bei derselben Tonhöhe hängt $a_{i} / a_{0}$ davon ab, einen wie starken Ton die betreffende Stimmgabel bei mittlerem Anschlag; entwickelt: d. h. also von ihrer Grösse, Bauart, Einklemmung u. s. w. Bei Stimngabeln verschiedener Höhe ausserdem noch von der Empfindlichkeit des normalen Ohres für den betreffenden Ton.

1) Schwendt und Wagner, Untersuchungen von Taubstummen S. $165 \mathrm{ft}$. Benno Schwabe, Basel 1899.

2) Vgl. hierüber Anhang II S. 51-54. 
Einige Beispiele, die ich der Arbeit von $\mathrm{Z}$ wa ardemaker und $\mathrm{Quix}{ }^{1}$ ) entnehme, werden das Gesagte erläutern.

Stimmgabel $G(N=96)$, Anfangsamplitude $a_{0}=120 \mu$.

Dämpfung $h=0,0481$. Hördauer $t_{n}=70$ Sec.

$\frac{a_{n}}{a_{0}}=e^{-h t_{n}}=e^{-0,0481 \cdot 70}=e^{-3,36}=3,38 \cdot 10^{-2}=\frac{1}{29,5}$.

Stimmgabel $g_{2}(N=768)$. Anfangsamplitude $a_{0}=40 \mu$.

Dämpfung $h=0,063$. Hördauer $t_{n}=131 \mathrm{Sec}$.

$$
\frac{a_{n}}{a_{0}}=e^{-h t_{n}}=e^{-0,063 \cdot 131}=e^{-8,25=2,6 \cdot 10^{-4} \cdot=\frac{1}{3860}}
$$

Nebmen wir an, dass bei einem Schwerhörigen für beide Stimmgabeln $\frac{t_{n}}{t_{k}}=m=\frac{1}{2}$ sei, so würde er also für beide Töne die gleiche "Hörschärfe" nach Hartmann-Bezold besitzen. In Wirklichkeit wäre seine Empfindlichkeit für den Ton $G$ :

$$
a_{n}^{2} / a_{k}^{2}=\left(a_{n} / a_{0}\right)^{2\left(1-\frac{1}{2}\right)}=a_{n} / a_{0}=\frac{1}{29,5}=3,38 \cdot 10^{-2}
$$

des normalen Ohres,

diejenige für den Ton $g_{2}$ :

$$
\begin{gathered}
a_{n}{ }^{2} / a_{k}{ }^{2}=\left(a_{n} / a_{0}\right)^{2\left(1-\frac{1}{2}\right)}=a_{n} / a_{0}=\frac{1}{3860}=2,6 \cdot 10^{-4} \\
\text { des normalen Ohres. }
\end{gathered}
$$

Für den Ton $g_{2}$ würde er also 130 Mal unempfindlicher sein wie für den Ton $G$.

Wenn man bei dem Schwerhörigen eine "Hörschärfe" $\frac{t_{n}}{t_{k}}=m$ $=\frac{1}{5}$ für beide Töne annimmt, wird die Sache noch schlimmer. Für den Ton $G$ wäre der Schwerhörige $4700 \mathrm{Mal}$, für $g_{2} 9,5 \cdot 10^{8} \mathrm{Mal}$ unempfindlicher als das normale Ohr. Wie man sieht, führt die Hartmann-Bezold'sche Methode unter Umständen zu falschen Resultaten, und man kommt bei richtiger Auswerthung der Stimmgabelversuche $\mathrm{zu}$ denselben grossen Zahlen für die Unempfindlichkeit Schwerhöriger, die ich oben bei directer Messung gefunden hatte, und die zunächst wohl etwas überraschend wirken.

Es liegt in der Natur der Sache, dass für tiefere Töne, für die das normale Ohr viel weniger empfindlich ist, bei einem Schwerhörigen die "Hörschärfe" $n$ sich kleiner ergibt wie für mittlere

1) $Z_{w}$ a ardemaker und Quix, 1. c. S. 376. 
Töne, so dass der Schluss nahe liegt, dass die Unempfindlichkeit für tiefere Töne besonders gross ist. In Wirklichkeit scheint, wie gesagt, gewöhnlich die Schwerhörigkeit mit der Tonhöhe zuzunehmen.

Vielleicht erweise ich den Herren Ohrenärzten einen Dienst, wenn ich im Anschluss an diese Besprechung einen Vorschlag für die Prüfung des Gehörs mittelst Stimmgabeln folgen lasse.

Wenn die Dämpfung $h$ der Stimmgabel bekannt ist, so ist es nur nöthig, die Zeit zwischen dem Eintritt der Reizschwelle des Kranken und des (normalen) eigenen Ohres zu beobachten $\left(t_{k}-t_{n}\right)$, ganz gleich, ob die Stimmgabel vorher stark oder leise angeschlagen war, oder wie weit sie von dem Ohr entfernt ist; nur muss das kranke und das normale Ohr unter den gleichen Umständen beobachten. Denn es handelt sich ja nur um die Bestimmung von $\left(a_{n} / a_{k}\right)^{2}$, und dies ist nach der obigen Formel $=e^{-2 h\left(t_{n}-t_{k}\right)} ; h$ ist als bekannt vorausgesetzt, $t_{n}-t_{k}$ wird beobachtet, $e^{-2 h\left(t_{n}-t_{k}\right)}$ wird herechnet oder kann in einer Tabelle nachgesehen werden.

$h$ muss für die betreffende Stimmgabel ein für alle Mal festgestellt werden. Es ist das an sich keine schwierige Operation, vielleicht würde jedoch auch die physikalisch-technische Reichsanstalt bereit sein, gleichzeitig mit der Aichung der Schwingungszahl der Stimmgabeln auch ihre Dämpfung $h$ zu messen. Natürlich müsste die Gabel von vornherein fest montirt sein und jedes Mal in bestimmter Art aufgestellt werden, damit die Dämpfung die gleiche bleibt.

\section{A $\mathbf{l l}$ h a $\mathbf{l l g} \mathbf{g}$.}

Berechnung der durch erzwngene Schwingungen einer Platte an einem entferuten Punkterregten Tonintensität.

Der Raum sei durch eine Ebene begrenzt; von einer Stelle dieser Ebene möge eine sinusförmige Schallbewegung ausgehen, durch welche die an die Ebene angrenzende Luft die normale Geschwindigkeit

$$
\frac{d \varphi}{d n}=u \cos 2 \pi(N t+\varepsilon)
$$

erhält. Dann ist das Geschwindigkeitspotential q für einen Punkt in der Entfernung $\varrho$

$$
\varphi=\frac{1}{2 \pi} \iint \frac{u \cos 2 \pi(N t-\varrho / \lambda+\varepsilon)}{\varrho} d f .
$$


Die Dimensionen der den Schall erzeugenden Fläche $f$ seinen klein gegen die Entfernung $\varrho$, für welche $\varphi$ berechnet werden soll; dann ist

$$
\varphi=\frac{\cos 2 \pi(N t-\varrho / \lambda+\varepsilon)}{2 \pi \varrho} \iint u d f .
$$

$f$ sei eine kreisförmige Platte von Radius $R$ (vgl. Fig. 11), $u_{0}=2 \pi N a_{0}$ die Geschwindigkeit des Mittelpunktes der Platte, $a_{0}$

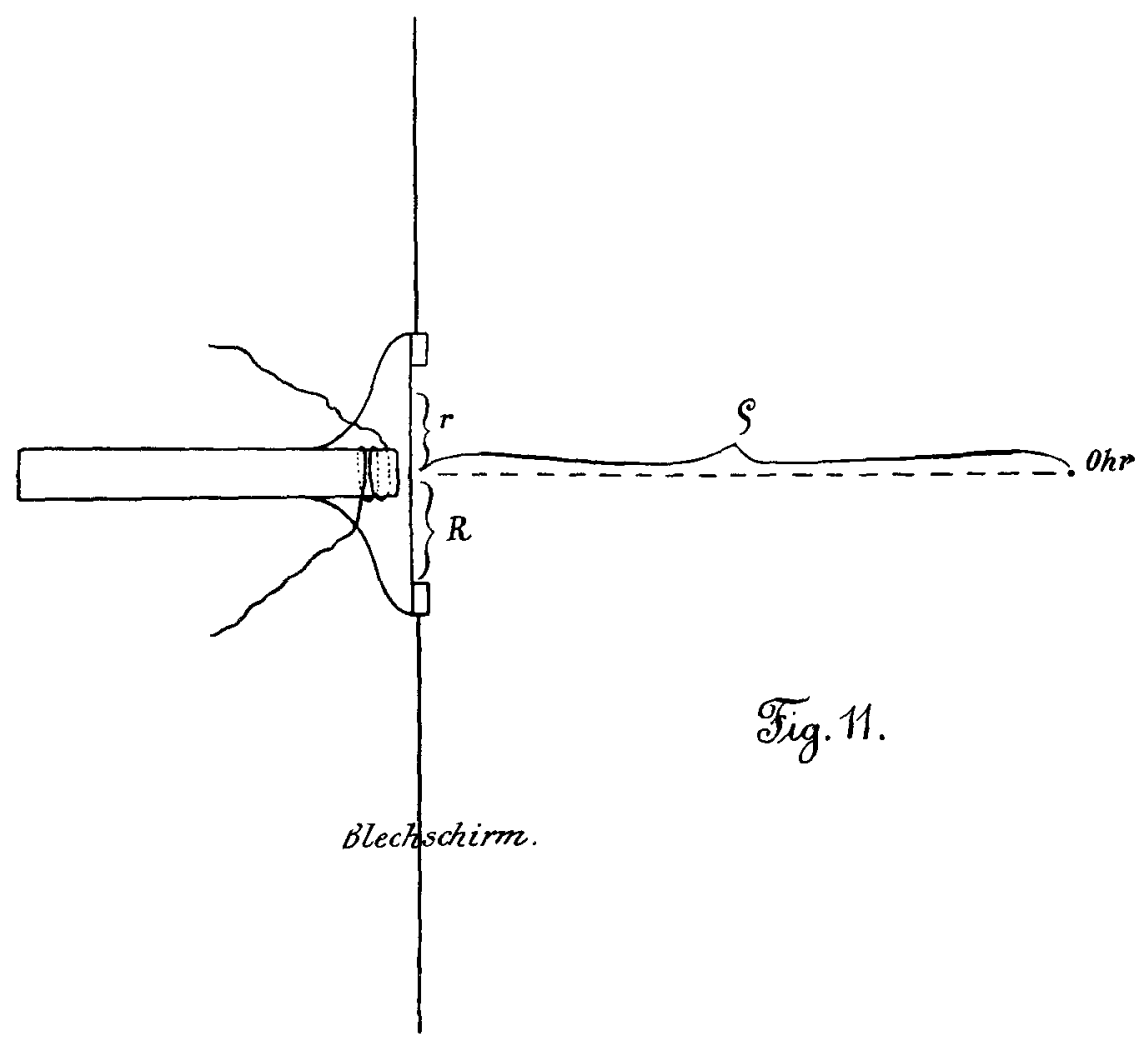

also seine Amplitude; ist $u$ die Geschwindigkeit irgend eines Punktes der Platte, $r$ seine Entfernung vom Mittelpunkt, und setzen wir voraus, dass $\frac{u}{u_{0}}$ nur eine Function von $r$ ist, so wird

$$
\varphi=\frac{2 \pi N a_{0}}{\varrho} \cos 2 \pi(N-\varrho / \lambda+\varepsilon) \int_{0}^{R} \frac{u}{u_{0}} r d r .
$$

Um das Integral auszuwerthen, müssen wir das Verhältniss $u / u_{0}$ in seiner Abhängigkeit von $r$ bezw. $r / R$ kennen, d. h. in unserem 
Ueb. die Empfindlichkeit des menschl. Ohres für Töne verschied. Höhe.

speciellen Fall müssen wir wissen, wie die Excursionen unserer Telephonplatte von der Mitte nach dem Rande zu abnehmen.

Unter der Voraussetzung, dass der tiefste Eigenton der Platte höher ist als die Schwingungszahl des erregenden Wechselstromes, ist die Form der Platte nicht wesentlich von derjenigen verschieden, die erzeugt wird durch eine ebenso vertheilte constante Kraft. Diese Form erhalten wir durch Integration der Differentialgleichung einer Platte:

$$
\Delta(\mathcal{I} u)=f(r)
$$

worin $f(r)$ die Form der Kraft angibt, unter folgenden Grenzbedingungen:

I. Der Rand der Platte ist eingeklemmt; für $r=R$ ist

$$
u=o \text { und } \frac{d u}{d r}=0 \text {. }
$$

II. In der Mitte ist keine Unstetigkeit vorhanden; für $r=0$ ist $u_{0},\left(\frac{d u}{d r}\right)_{0},\left(\frac{d^{2} u}{d r^{2}}\right)_{0},\left(\frac{d^{3} u}{d r^{3}}\right)_{0}$ endlich.

In dem von mir benutzten Telephon steht nur ein Magnetpol der Mitte der Platte gegenüber. Mithin ist die Form der Kraft so, dass sie in der Mitte am grössten ist und nach dem Rande zu abnimmt. Sie kann also angenähert dargestellt werden durch die Function

$$
f(r)=(R-r)^{\prime \prime},
$$

Je höher $p$ ist, desto schneller nimmt die Kraft nach dem Rande $\mathrm{zu}$ ab.

Um die Differentialgleichung $I(I x)=f(r)$ zu integriren, verfuhr ich auf den Rath von Prof. Som merfeld-Aachen in folgender Art:

Statt $r$ wird eine Hülfsvariable $x=\ln r$ eingefülırt; dann wird

$$
d u=\frac{d^{2} u}{d r^{2}}+\frac{1}{r} \frac{d u}{d r}=\frac{d^{2} u}{d \tau^{2}} \cdot \frac{1}{r^{2}}=\frac{d^{2} u}{d \tau^{2}} \cdot e^{-2 \tau} \text {. }
$$

Darauf wird noch eine Hülfsfunction $v=I(u)$ eingeführt. Dann lautet die zu integrirende Gleichung:

$$
\mathcal{L}(\Delta u)=\Delta(v)=e^{-2 x} \frac{d^{2} v}{d \tau^{2}}=f(r)=f_{1}(x) .
$$

Es wird also zunächst die Gleichung

$$
\frac{d^{2} v}{d \tau^{2}}=e^{2 \tau} f_{1}(\tau) \text { integrirt, }
$$


dann das so erhaltene $v$ in die Gleichung $\frac{d^{2} u}{d \tau^{2}}=e^{2 \tau} \cdot v$ eingesetzt und wieder integrirt und schliesslich $\tau=\ln r$ wieder eingeführt.

Als Beispiel sei der Fall $p=o f(r)=1$ ausführlicher dargestellt :

$$
\begin{aligned}
& \frac{d^{2} v}{d \tau^{2}}=e^{2 \tau} \quad v=\frac{e^{2 \tau}}{4}+A \tau+B \\
& \frac{d^{2} u}{d \tau^{2}}=e^{2 \tau} \cdot v=\frac{e^{4 \tau}}{4}+A \tau e^{2 \tau}+B e^{2 \tau} \\
& u=\frac{e^{4 \tau}}{64}+\frac{B-A}{4} e^{2 \tau}+\frac{A}{4} \tau e^{2 \tau}+C \tau+D \\
& u=\frac{r^{4}}{64}+\frac{B-A}{4} r^{2}+\frac{A}{4} r^{2} \ln r+C \ln r+D .
\end{aligned}
$$

Nach der Grenzbedingung II soll in der Mitte $(r=0)$ Alles endlich bleiben; daher ist $A=o$ und $C=0$.

$$
u=\frac{r^{4}}{64}+B \frac{r^{2}}{4}+D \text {. }
$$

Nach Grenzbedingung I ist für $r=R \quad u=o$ und $\frac{d u}{d r}=0$.

Dies gibt

$$
B=-\frac{R^{2}}{8} \quad D=+\frac{R^{4}}{64}
$$

und

$$
\begin{gathered}
u=\frac{r^{4}}{64}-\frac{r^{2}}{32} R^{2}+\frac{R^{4}}{64} \quad u_{0}=\frac{R^{4}}{64} \\
\frac{u}{u_{0}}=\left(\frac{r}{R}\right)^{4}-2\left(\frac{r}{R}\right)^{2}+1 .
\end{gathered}
$$

In derselben Weise ergibt sich für:

$$
\begin{gathered}
f(r)=R-r \\
\quad \frac{u}{u_{0}}=1-\frac{290}{129}\left(\frac{r}{R}\right)^{2}+\frac{225}{129}\left(\frac{r}{R}\right)^{4}-\frac{64}{129}\left(\frac{r}{R}\right)^{5} \\
f(r)=(R-r)^{2} \\
\frac{u}{u_{0}}=1-\frac{205}{83}\left(\frac{r}{R}\right)^{2}+\frac{225}{83}\left(\frac{r}{R}\right)^{4}-\frac{128}{83} \cdot\left(\frac{r}{R}\right)^{5}+\frac{25}{83} \cdot\left(\frac{r}{R}\right)^{6} . \\
f(r)=(R-r)^{3} \\
\frac{u}{u_{0}}=1-\frac{10052}{3764}\left(\frac{r}{R}\right)^{2}+\frac{14700}{3764}\left(\frac{r}{R}\right)^{4}-\frac{12544}{3764}\left(\frac{r}{R}\right)^{5} \\
+\frac{4900}{3764}\left(\frac{r}{R}\right)^{6}-\frac{768}{3764}\left(\frac{r}{R}\right)^{7} .
\end{gathered}
$$


Ueb. die Empfindlichkeit des menschl. Ohres für Töne verschied. Höhe.

Hieraus berechnet sich das Geschwindigkeitspotential

für:

$$
\varphi=\frac{2 \pi N a_{0}}{\varrho} \cos 2 \pi\left(N t-\varrho(\lambda+\varepsilon) \int_{0}^{R} \frac{u}{u_{0}} r d r\right.
$$

$$
\begin{array}{ll}
f(r)=1 & \varphi=0,167 \cdot \frac{2 \pi N a_{0} R^{2}}{\varrho} \cos 2 \pi(N t-\varrho / \lambda+\varepsilon), \\
f(r)=r-R & \varphi=0,158 \cdot \frac{2 \pi N a_{0} R^{2}}{\varrho} \cos 2 \pi(N t-\varrho / \lambda+\varepsilon), \\
f(r)=(r-R)^{2} & \varphi=0,152 \cdot \frac{2 \pi N a_{0} R^{2}}{\varrho} \cos 2 \pi(N t-\varrho / \lambda+\varepsilon), \\
f(r)=(r-R)^{2} & \varphi=0,147 \cdot \frac{2 \pi N a_{0} R^{2}}{\varrho} \cos 2 \pi(N t-\varrho / \lambda+\varepsilon) .
\end{array}
$$

Von der Form der Kraft ist $\varphi$ also nur in geringem Maasse abhängig; das Zahlencoëfficient nimmt langsam ab, je mehr die Kraft nach der Mitte der Platte concentrirt wird. Da der Querschnitt des Telephonmagnets klein gegen die Fläche der Telephonplatte war und er sehr nahe an die Platte herangeschraubt wurde, so wählen wir $f(\boldsymbol{r})=(\boldsymbol{r}-R)^{3}$ und den Zahlencoëfficienten 0,147 .

Das Geschwindigkeitspotential $\varphi$ ist mit der Excursion $\xi$ und der Geschwindigkeit $\frac{d \xi}{d t}$ eines Luftheilchens verbunden durch die Gleichungen :

$$
\frac{d \xi}{d t}=2 \pi N \xi=\frac{d \varphi}{d \varphi} \text {. }
$$

Die Druckdifferenz ist gegeben dureh

$$
\delta p=-\frac{p_{0} k^{2}}{c^{2}} \frac{d \tau}{d t}
$$

worin $l k$ das Verhältniss der spec. Wärmen, $c$ die Schallgeschwindigkeit und $p_{0}$ der Luftdruck ist.

Die Schwingungsenergie pro Secunde, unser eigentliches Maass der Empfindlichkeit, ist gegeben durch

$$
A=\int_{1}^{1} \frac{d \xi}{d t} \delta p d t=-\frac{p_{0} z_{i}}{c^{2}} \int_{0}^{1} \frac{d \varphi}{d \varphi} \cdot \frac{d \varphi}{d t} d t .
$$

Hiernach ergibt sich:

$$
\begin{gathered}
\frac{d \xi}{d t}=2 \pi N \xi=0,14 \gamma^{2 \pi N a_{0} R^{2}}\left\{\frac{2 \pi}{\lambda} \sin 2 \pi\left(N t-\frac{\varrho}{\lambda}+\varepsilon\right)\right. \\
\left.-\frac{\cos 2 \pi(N t+\varrho / \lambda+\varepsilon)}{\varrho}\right\}=0,147 \frac{2 \pi N a_{0}}{\varrho^{2}} R^{2} \sqrt{1+\left(\frac{2 \pi}{\lambda} \varrho\right)^{2}} \\
\sin 2 \pi\left(N t-\frac{\varrho}{\lambda}+\varepsilon^{1}\right) .
\end{gathered}
$$




$$
\begin{gathered}
\frac{\delta p}{p_{0}}=-\frac{k}{c^{2}} \cdot \frac{d \varphi}{d t}=0,147 \cdot \frac{k}{c^{2}} \cdot \frac{(2 \pi N)^{2} a_{0}}{\varrho} . \\
R^{2} \sin 2 \pi\left(N t-\frac{\varrho}{\lambda}+\varepsilon\right) .
\end{gathered}
$$

Die Energie, die in der Zeiteinheit durch die Flächeneinheit geht, ergibt sich zu

$$
A=\frac{(0,147)^{2} \cdot p_{0} \cdot k \cdot(2 \pi N)^{4} a_{0}{ }^{2}}{2 c^{3} \varrho^{2}} .
$$

Mit der relativen Druckamplitude, Max. $\left(\frac{\delta p}{p_{0}}\right)=\Delta$, ist $A$ durch die einfache Gleichung verbunden: $A=\frac{c \cdot p_{0}}{2} \cdot \Delta^{2}=1,19 \cdot 10^{10} \cdot \Delta^{2} \operatorname{Erg}=1,21 \cdot 10^{17} \cdot A^{2} \mu \mu \mathrm{mg}$ für $0^{\circ} \mathrm{C}$. und $760 \mathrm{~mm} \mathrm{Hg}$ Barometerstand.

Von den gewöhnlichen Formeln für Schallwellen unterscheiden sich diese Gleichungen dadurch, dass die Geschwindigkeit und die Amplitude in der Nähe der Schallquelle verhältnissmässig zu gross sind und nicht proportional der Entfernung, sondern schneller abnehmen ${ }^{1}$ ). Anders ist es bei der Druckdifferenz, die stets proportional der Entfernung abnimmt. Letztere ist daher ein richtigeres Maass für die Tonintensität, die ebenfalls stets umgekehrt proportional dem Quadrat der Entfernung ist. Amplitude und Geschwindigkeit können bei nichtebenen Wellen erst in Entfernungen, die gross sind gegen die Wellenlänge, als Maass der Tonenergie dienen.

Man könnte darüber Zweifel hegen, ob die verhältnissmässig grossen Luftamplituden in der Nähe der Schallquelle, wenn sie auf ein Hinderniss - z. B. auf den Kopf des Hörenden - stossen, nicht doch eine Tonintensität erzeugen, welche grösser ist als die, welche für freie Ausbreitung aus der Druckdifferenz sich berechnet.

Um diese Frage experimentell zu entscheiden, wurden einige Versuche mit einem Telephon als Tonquelle und einem Resonator mit eingestimmter Manometerkapsel und Spiegelübertragung als Tonempfänger angestellt. Die Einrichtung ist in einer früheren Arbeit beschrieben ${ }^{2}$ ). Fs wurde, wie oben S. 20, ein grosses Blech mit einem $5 \mathrm{~cm}$ weiten Loch benutzt. Der Resonator wurde mit seiner Oeffnung an das Loch gebracht. Das als Tonquelle dienende Telephon

1) Wie bei allen nichtebenen Wellen. Vgl. Helmholtz, Vorträge über Theoret. Physik Bd. 3 S. 170-173.

2) Dissert. S. 6-12. 
wurde nun in verschiedene Abstände (b) von dem Resonator gebracht und dessen Ausschläge durch ein Fernrobr mit Oculartheilung gemessen. Es ergab sich folgende Tabelle (XVII). Die Schwingungszahl des Tones war $N=192$, die Wellenlänge bei $18^{\circ} \mathrm{C}$. $\lambda=179 \mathrm{~cm}$.

Das Product $b \beta$ steigt zwar bei kleinen Werthen von $b$ etwas an, wahrscheinlich, weil der Schall zwischen Blech und Telephongehäuse sich nicht mehr frei ausbreiten kann. Jedoch ist es immerhin genügend constant, um als Beweis dafür zu dienen, dass die Amplitude des Resonators proportional der Druckdifferenz und nicht der Luftamplitude ist. Wenn Letzteres der Fall wäre, so hätten die Resonatorausschläge von den niedrigsten Werthen 5,5 bezw. 5,1 in der Tabelle XVII wie $\beta^{\prime}$ ansteigen müssen ${ }^{1}$ ).

Tabelle XVII.

Tonintensität in der Nähe einer Schallquelle.

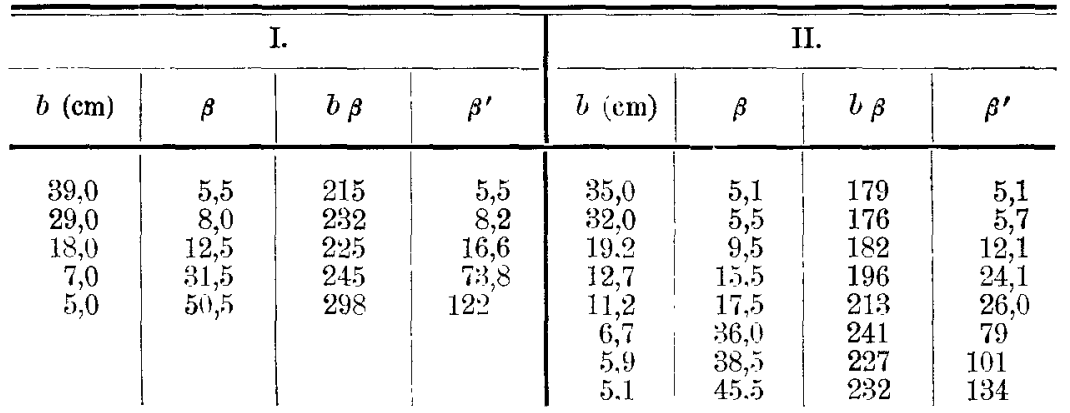

In derselben Weise wurde nachgewiesen, dass bei der getroffenen Versuchsanordnung das Helmholtz'sche Reciprocitätsgesetz gültig ist, was für die obigen Versuche bei hohen Tönen von Bedeutung ist. Der Blechschirm wurde von dem Resonator auf die Tonquelle zu entfernt. Dabei nahm in Folge von Reflexion und Beugung der Ausschlag zunächst stark ab, um dann wieder zu steigen, bis, wenn der Schirm unmittelbar vor dem Telephon stand, der ursprüngliche Ausschlag wieder erreicht wurde; ein Beispiel einer Versuchsreihe sei hier angeführt, $a$ Entfernung zwischen Schirm und Telephon, $b$ zwischen Schirm und Resonator (Fig. 12).

1) Bei der Messung der Tonintensität durch Rayleigh'sche Scheibchen (E. Grimseh1, Wiedemann's Ann. Bd. 34 S. 1028. 1888. - W. König, Wiedemann's Ann. Bd. 43 S, 43. 1891), welche auf Luftströmung reagiren, dürfte sich ein anderes Resultat ergeben. 


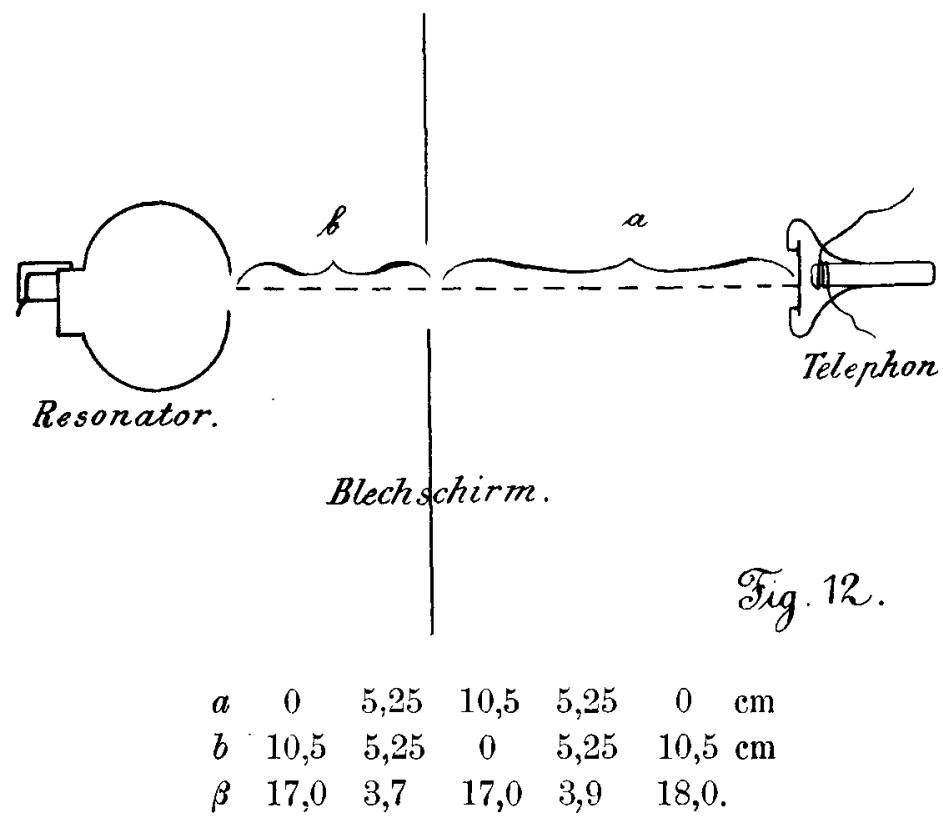

Demnach können Tonquelle und Tonempfänger mit einander vertauscht werden.

\section{A n h a $\mathbf{n g}$ II.}

Bemerkungen zu den Arbeiten der Herren Zwaardemaker und Quix.

In einer Reihe vor Kurzem erschienener Arbeiten haben die Herren $\mathrm{Z}$ wa ardemaker und Quix, wie oben erwähnt, ebenfalls Versuche über die relative Empfindlichkeit des Ohres für Töne verschiedener Höhe angestellt. Danach ist die an der Reizschwelle das Ohr pro Secunde treffende Energie in dem ganzen von ihnen untersuchten Tonbereich ( $N=32$ bis $N=12288$ ) von derselben Grössenordnung; setzen wir die Empfindlichkeit für den Ton 32 $=1$, so steigt sie bis zum Ton $f_{4}$ (2732) bis auf ca. 80 , um dann bei $g_{6}(12288)$ auf ca. 13 wieder zu sinken. Nach meinen Versuchen ist die Schwellenenergie für den Ton $N=50$ ca. 100 Millionen Mal grösser wie die des Tones $N=2000$, so dass das Maximum der Empfindlichkeit des Ohres relativ etwa eine Million Mal höher ist als bei $Z$ wa a rdemaker und $Q u i x$, - eine Differenz, wie sie in den exacten Wissenschaften bei zwei annähernd gleichzeitig erschienenen Arbeiten wohl einzig dasteht. 
Mit zwei so von einander abweichenden Resultaten ist der Wissenschaft wenig gedient, und damit nicht das Vertrauen $\mathrm{zu}$ meinen Versuchen darunter leidet, habe ich die Pflicht, den Nachweis zu versuchen, dass die Zahlen von $Z$ wa ardemaker und $Q u i x$ falsch sind.

Nach der Art der Tonerzeug̣ung zerfällt ihre Untersuchung in zwei Theile: von den Schwingungszahlen 32 bis 1024 dienten Stimmgabelı, von 1024-12288 Pfeifen verschiedener Art als Tonquelle. Beginnen wir mit dem letzten Theil. Der Ton der Pfeife wurde von einem entfernten Zimmer aus beobachtet und die Luftzufuhr zur Pfeife so lange vermindert, bis der Ton aus dem fünften Zimmer gerade noch, aus dem sechsten Zimmer gerade nicht mehr gehört wurde. Die Tonintensität wurde gleich der Energie des der Pfeife zugeführten Luftstromes gesetzt und angenommen, dass die Schwächung bis zum sechsten Zimmer bei allen Schwingungszahlen dieselbe sei.

Obgleich nun auch hier Einiges zu Bedenken Veranlassung gibt - z. B. ob nicht besonders bei ganz hohen Pfeifen nur ein kleiner Bruchtheil der Luftenergie in Tonenergie umgesetzt wird, ob nicht durch Beugung an den fünf Thüröffnungen die tiefen Töne mehr geschwächt werden wie die hohen, und schliesslich, ob die im Zimmer stets auftretenden ausgeprägten Maxima und Minima der Tonintensität ${ }^{1}$ ) die Resultate nicht stark beeinflusst haben können -, so sind die Fehlerquellen hier doch verhältnissmässig geringfügiger Natur. Dementsprechend weichen für diesen Tonbereich unsere Resultate auch nicht sehr stark von einander $a b$ : Bei den Herren Zwaardemaker und Quix steigt die Empfindlichkeit zwischen den Tönen 1024 und 2732 auf etwa den doppelten Werth, um dann bis $N=12288$ bis auf etwa $1 / \pi$ des Maximalwerthes wieder zu sinken. Bei meinen Versuchen steigt die Empfindlichkeit von $N=$ 1024 bis zu dem an der gleichen Stelle befindlichen Maximum $(N=2800)$, wo sie etwa den dreifachen Werth erreicht, um von da $a b$ bis 12000 auf etwa $1 / 15$ des Maximalwerthes $\mathrm{zu}$ sinken: Differenzen, die durchaus in die Grenzen der Beobachtungsfehler fallen.

Anders liegt die Sache bei dem ersten Theil, wo die tieferen Töne untersucht wurden; es wurde das Abklingen von Stimmgabeln bis zur Reizschwelle des Tones beobachtet und aus Amplitude,

1) Vgl. Dissert. S. $60-64$. 
Dämpfung und Form der Stimmgabel die Schwellenenergie des Tones berechnet.

Bei der Berechnung wurde die Tonenergie gleich dem Energieverlust der Stimmgabel in der Zeiteinheit gesetzt. Nun geht nur ein kleiner Bruchtheil der Gesammtenergie in Schallschwingungen über; der bei Weitem grössere Theil wird durch innere Reibung in Wärme verwandelt oder geht durch den Stiel an die Umgebung verloren. Bei einer Stimmgabel mit Resonanzkasten schätzt Wead ${ }^{1}$ ) den Bruchtheil auf $1 / 15$; bei Stimmgabeln ohne Resonanzkasten, wie $\mathrm{Z}$ wardemaker und $\mathrm{Quix}$ sie gebrauchten, ist er noch viel kleiner. Die Art der Einklemnung beeinflusst nach Z waardemaker und Quix stark die Dämpfung der Stimmgabeln, während offenbar die ausgesandte Tonintensität bei gleicher Amplitude der Gabel die gleiche bleibt. Demnach hängt der in Tonenergie verwandelte Bruchtheil der Gesammtenergie von der Art der Einklemmung ab. Hierin liegt auf jeden Fall eine grosse Unsicherheit, die zur principiellen Fehlerquelle wird, falls der Bruchtheil von der Schwingungszahl abhängig ist. $O b$ dies in der That der Fall ist, lässt sich natürlich schwer sagen. Es scheint mir jedoch, als ob der Ton der schnell abklingenden hohen Stimmgabeln nicht in Verhältniss stärker wäre wie jener der tieferen Gabeln, so dass also bei hohen Gabeln verhältnissmässig wenig Energie in Schallwellen überginge.

Nur so viel steht fest, dass bei derselben Stimmgabel die Tonintensität proportional $a^{2}$, dem Quadrat der Amplitude wächst, und gerade dies physikalische Grundgesetz wird von den Verfassern als unrichtig angesehen und die an die Luft abgegebene Tonenergie proportional $a^{1,2}$ gesetzt.

Da ähnliche Auffassungen auch noch sonst, besonders in der medicinischen Literatur, herumspuken, und es nicht angängig ist, dass ohne Widerspruch auf Grund unrichtig angestellter bezw. unrichtig gedeuteter Versuche an den physikalischen Grundprincipien gerüttelt wird, so muss ich etwas näher auf diesen Punkt eingehen.

Eine Proportionalität der Tonenergie mit $a^{1,2}$ ist schon aus dem Grunde nicht möglich, weil man beim Uebergang zu immer kleineren Amplituden schliesslich auf Widersprüche mit dem Energieprincip

1) Wead, Americ. Journ. of Sciense (3) vol. 36 p. 193.1883. 
kommt. Der Annahme nach ist die Stimmgabelenergie $=P \cdot a^{2}$, die von ihr in der Zeiteinbeit an die Luft abgegebene Energie $=P \cdot a^{1,2} \cdot F$, worin $F$ eine Constante bedeutet, welche durch Vergleich mit den Messungen von Töpler und Boltzmann zu 0,000618 gefunden wurde. Im Laufe des Abschwingens möge nun $a$ voun Anfangswerthe 1 auf ${ }^{1 / 20000}$ gesunken sein. Dann ist die Stimmgabelenergie $=P \cdot 2,5 \cdot 10^{-9}$, die des Tones jedoch $=\frac{P}{(20000)^{1,2}} \cdot F$ $=P \cdot 4,2 \cdot 10^{-9}$. Demnach würde die in der Zeiteinheit abgegebene Energie grősser sein als die überhaupt in der Stimmgabel noch vorhandene. Die Wirkung dieses principiellen Fehlers macht sich auch mehrfach in den Zablen von $Z_{\text {waardemaker und } \mathrm{Quix}}$ bemerklich, indem z. B. in Tabelle $\mathrm{V}$ bei $c_{2}$ der totale Energieverlust der Gabel in 0,1 Secunde 0,0024 beträgt, während der Theil derselben, welcher an die umringende Luft in 0,1 Secunde übertragen wird $=7,686 \cdot F=0,0048$ sein soll; ähnlich bei $c_{3}$ u. s. w.

Die Frage, wie die Amplitude der Luftbewegung von der Amplitude der erregenden Stimmgabel abhängt, habe ich in der jerlenfalls viel directeren Art untersucht, dass ich die Luftschwingungen auf einen Resonator mit Spiegelablesung (S. 43) wirken liess. Die Stimmgabel wurde mittelst eines Elektromagneten durch einen in der Periode der Stimmgabel unterbrochenen Strom verschiedener Stärke erregt und ihre Amplitulen (a) mittelst eines angeklebten kleinen Spicgels in Fernrohr beobahtet. Gleichzeitig wurden in derselben Weise die Ausschlïge des Resonators ( $\beta$ ) gemessen. Die Ablesungen waren wegen kleiner Erschütterungen des Gebäudes nur auf circa 0,5 Scalentheile genau. Die Resultate sind in der folgenden Tab. XVIII angegeben.

Es ergibt sich offenbar innerhalb der Ablesefehler genaue Proportionalität.

In derselben Weise wurde bei einem Telephon als Tonquelle die Proportionalität der Lufthewegung mit der Amplitude der Telephonplatte bezw. der Amplitude des Stromes nachgewiesen. In der folgenden Tabelle bedeutet $\gamma$ den Ausschlag des Dynanometers, der also proportional dem Quadrat der Stromamplitude ist.

(Siehe Tabelle X1X 5. 52.)

Die Annahme, dass die an die Luft ahgegebene Tonenergie proportional $a^{1,2}$ sei, begründen $Z$ wa a rdemaker und $Q u$ ix eimmal mit dem Hinweis auf die bekannten Versuche von Vierordt und Ober- 


\section{Tabelle XVIII.}

Abhängigkeit der Amplitude der Luftbewegung $(\beta)$ von der Amplitude der erregenden Stimmgabel $(a) ; \Delta a / \beta=$ Abweichung vom Mittelwerth.

\begin{tabular}{c|c|c|c}
\hline \multicolumn{1}{c|}{$a$} & $\beta$ & $a / \beta$ & $\alpha \boldsymbol{\alpha} / \boldsymbol{\beta}$ \\
\hline 2,5 & 3,5 & 0,71 & $-0,01$ \\
3,1 & 5,0 & 0,62 & $\pm 0,10$ \\
4,0 & 6,0 & 0,67 & $\pm 0,05$ \\
5,5 & 7,3 & 0,75 & $+0,03$ \\
10,5 & 13,5 & 0,77 & $+0,04$ \\
23,5 & 31,0 & 0,76 & $+0,04$ \\
21,0 & 29,0 & 0,72 & $\pm 0,00$ \\
9,0 & 12,5 & 0,72 & $\pm 0,00$ \\
5,0 & 7,5 & 0,67 & $\pm 0,05$ \\
4,5 & 6,0 & 0,75 & $+0,03$ \\
3,5 & 4,5 & 0,77 & $+0,05$ \\
2,8 & 3,8 & 0,74 & $+0,02$
\end{tabular}

Tabelle XIX.

Abhängigkeit der durch ein Telephon erzeugten Schallbewegung von der Stromamplitude.

\begin{tabular}{r|c|c|c}
\hline$\gamma$ & $\beta$ & $\beta / \sqrt{\gamma}$ & $\alpha(\beta / \sqrt{\gamma})$ \\
\hline 22 & 9,5 & 2,02 & $+0,06$ \\
40 & 13 & 2,05 & $+0,09$ \\
82 & 18 & 1,99 & $+0,03$ \\
205 & 28 & 1,95 & $\pm 0,01$ \\
210 & 28,5 & 1,97 & $+0,01$ \\
130 & 21 & 1,85 & $-0,11$ \\
80 & 17 & 1,90 & $-0,06$ \\
35 & 11,5 & 1,94 & $-0,02$
\end{tabular}

beck, wonach von einer Platte, die durch eine fallende Kugel in Schwingungen versetzt wird, ein Schall ausgeht, der nicht der Fallhöhe $h$ der Kugel proportional ist, sondern $h^{0,6}$. Es ist hiergegen zu bemerken, dass bei jenen Versuchen die Verhältnisse ganz anders liegen, indem durch die fallende Kugel zunächst die Platte in Bewegung versetzt wird und durch diese erst die umgebende Luft. Die Schwingungsenergie einer Stimmgabel wächst ebenfalls nicht proportional der Stärke des Anschlages, die Tonintensität einer Pfeife nicht proportional der Energie des zugeführten Luftstromes, und die Leistung einer Maschine ist nicht proportional der verbrauchten Kohlenmenge. 
Hauptsächlich fusst die Annahme jedoch auf Stimmgabelversuchen von Herrn $\mathrm{Quix}{ }^{1}$ ). Derselbe beobachtete aus verschiedenen Entfernungen das Abklingen einer Stimmgabel, bis die Reizschwelle seines Ohres erreicht war, und maass die den verschiedenen Entfernungen entsprechenden Schwellenamplituden der Stimmgabel. Indem nun die Abnahme der Schallintensität umgekehrt proportional dem Quadrat des Abstandes zwischen Beobachter und Toncentrum der Stimmgabel gesetzt wurde, ergab sich als empirisches Resultat die Beziehung: Tonintensität proportional $a^{1,2}$, wodurch die Versuchsergebnisse scheinbar am besten dargestellt wurden.

Abgesehen davon, dass eine grosse Unsicherheit darin liegt, dass die Versuche auf der schwierigen Reizschwellenmessung begründet sind, scheint mir die Deutung der Resultate falsch zu sein: die Unregelmässigkeit liegt nicht in der Potenz der Amplitude, sondern darin, dass das Gesetz von der Abnahme der Schallintensität umgekehrt proportional dem Quadrat der Entfernung in der Nähe vler Stimmgabel keine Gültigkeit hat.

Wie die Herren $\mathrm{Z}$ wa ardemaker und Quix selbst eingehend untersucht haben, ist die Stimmgabel eine in hohem Maasse "polarisirte" Tonquelle, die nach verschiedenen Richtungen Schallwellen sehr verschiedener Intensität und Phase aussendet, erst in grosser Entfernung ${ }^{2}$ ) werden sie zu regelmässigen Kugelwellen. In der Nähe der Stimmgabel ist die Ausbreitung wegen Fnergieanstauschs und Interferenz durchaus unregelmässig. In den Hauptschallrichtungen speciell ist durch Energiealogithe an die schallschwachen Richtungen die Abnahme der Amplitude viel sehneller als proportional der Entfernung. Dazu kommt noch die Refiexion an den Wänden des Zimmers, die Maxima und Minima hervorruft, wodurch ebenfalls die regelmässige Ausbreitung des Schalles verhindert wird.

In scinen Hauptversuchen umgab Herr $Q$ uix vorsichtshalber, um die Reflexion an den Wänden des Zimmers zu vermeiden, seine Stimmgabel mit einer Hülle von Watteschirmen, in denen nur zum Heraustreten des Schalles ein etwa handflächengrosses Loch gelassen wurde, dem gegenüber das Ohr des Beobachters in verschiedene Entfernungen gebracht wurde. Hierbei spielt die Polarität der Tonquelle keine so wesentliche Rolle mehr, jedoch ist die Beugung des

1) Quix, Onderz. Physiol. Labor. der Utrerhtsche Hoochgeschool 5 de Reeks Deel 3 p. 240.

2) Rayleigh hat auch für grössere Abstände von der Stimmgabel die Hörweite proportional der Amplitude gefunden, 1. c. 
Schalles zu berücksichtigen. Bekannt sind ja die entsprechenden Versuche in der Optik: macht man den Beugungsspalt enger und enger, so wird das Spaltbild immer breiter, bis schliesslich nur noch diffuses Licht von dem Spalte selbst herkommt. Dasselbe ist nun auch beim Schall der Fall ${ }^{1}$ ), wenn die Oeffinung von derselben Grössenordnung ist, wie die Wellenlänge $(\lambda)$, und um so mehr, wenn sie wie hier beträchtlich kleiner ist als $\lambda$. (Die Oeffnung bei Herrn $Q u$ in $x$ betrug ca. $10 \mathrm{~cm}$ Durchmesser, $\lambda$ war $=400$ bezw. $800 \mathrm{~cm})$. Fine gegen die Wellenlänge kleine Oeffnung wirkt so, als wenn von ihr der Schall ausginge. Herr Quix hätte also die Entfernung von ihr aus messeu müssen, nicht von der Stimmgabel; dann wären seine Resultate wohl auch ganz andere geworden. Um das Gesagte experimentell zu erhärten, wurden einige Beugungsversuche mit dem Telephon als Tonquelle und dem Resonator als Schallempfänger angestellt. Zwischen beide wurde ein grosser Blechschirm mit einer $5 \mathrm{~cm}$ weiten Oeffnung gebracht. Die Entfernung zwischen Schirm und Tonquelle sei $a$, diejenige zwischen Schirm und Resonatoröffnung $b$. Die folgende Tabelle gibt die Resultate zweier Versuchsreihen, $\beta$ ist darin der Ausschlag des Resonators.

Tabelle XX.

Versuche über die Beugung des Schalles. $a=10 \mathrm{~cm}$.

\begin{tabular}{|c|c|c|c|c|}
\hline$b$ & $\beta$ & $b \cdot \beta$ & $\beta(a+b)$ & $\beta^{0,6}(a+b)$ \\
\hline $\begin{array}{r}3,5 \\
6,5 \\
8,0 \\
13,2 \\
16,0\end{array}$ & $\begin{array}{r}14,4 \\
7,4 \\
5,1 \\
4.8 \\
4,0\end{array}$ & $\begin{array}{l}50,5 \\
48,1 \\
51,4 \\
63,3 \\
64,0\end{array}$ & $\begin{array}{c}195 \\
122 \\
91,8 \\
111 \\
104\end{array}$ & $\begin{array}{l}66 \\
55 \\
48 \\
60 \\
60\end{array}$ \\
\hline \multicolumn{5}{|c|}{$a=5 \mathrm{~cm}}$. \\
\hline $\begin{array}{r}3,6 \\
5,4 \\
6,3 \\
8,8 \\
9,8 \\
13,2 \\
13,3 \\
14,3 \\
16,5 \\
21,0\end{array}$ & $\begin{array}{r}28,8 \\
17,8 \\
15,2 \\
10,1 \\
8,5 \\
6,6 \\
7,1 \\
6,4 \\
6,1 \\
4,4\end{array}$ & $\begin{array}{r}104 \\
96 \\
98 \\
89 \\
84 \\
87 \\
94 \\
92 \\
100 \\
92\end{array}$ & $\begin{array}{l}248 \\
185 \\
171 \\
139 \\
126 \\
120 \\
130 \\
124 \\
131 \\
114\end{array}$ & $\begin{array}{l}65 \\
59 \\
58 \\
55 \\
54 \\
57 \\
59 \\
59 \\
64 \\
63\end{array}$ \\
\hline
\end{tabular}

1) Vgl. Helmholtz, Vorlesungen üb. theoret. Physik Bd. 3 S. 191-193. Rayleigh, Theory of sound vol. $2 \S 280-281$. 
In Anbetracht des Umstandes, dass die Oeffnung für kleinere Entfernungen $b$ nicht als punktförmig anzusehen ist, und dass auf grössere Entfernungen die Reflexion an den Wänden des Zimmers schon merklich sein dürfte, ist die Constanz von $\beta b$ in beiden Versuchsreihen genïgend. Jedenfalls ist $\beta(a+b)$ sehr viel weniger constant. Dieses kann man, wie die letzte Columne zeigt, wieder redressiren, indem man $\beta$ den Exponenten 0,6 beilegt, dann ist $\beta^{0,6} \cdot(a+b)$ oder auch $\beta^{1,2}(a+b)^{2}$ wieder einigermaassen constant. Auf diese Weise ist Herr Qu ix zu seinem Exponenten 1,2 gekommen.

Ich glaube hiermit den Beweis geliefert zu haben, dass die Ampliturle der Luftschwingungen proportional der Amplitude des schwingenden Körpers ist, und ferner gezeigt zu haben, wie die Herren $\mathrm{Zwa}$ ardemaker und Quix zu ihrer falschen Annahme gekonmen sind, dass die Tonenergie proportional $a^{1,2}$ sei.

Ehe ich zur Berechnung des Einflusses dieser Fehlerquelle auf ihre Resultate übergehe, möchte ich noch eine zweite Fehlerquelle besprechen. Die Schwellenamplidute der Stimmgabeln konnte in den meisten Fällen nicht direct beobachtet, sondern musste berechnet werden. $\mathrm{Zu}$ diesem $\mathrm{Z}$ wecke benutzten sie eine Formel von Stefanini, nach der die Amplitude einer Stimmgabel nicht proportional $a e^{-7 t t}$, sondern $a e^{-h t 0.9}$ fällt.

Die empirische Formel von Stef a nin i bezieht sich ausschliesslich auf lie von ihm benutzten Stimmgaheln und ist darauf begründet, dass der Dämpfungsfactor $h$ nicht constant, sondern bei seinen Versuchen hei grosser Amplitude grösser ist als hei kleiner. Nach Ver-

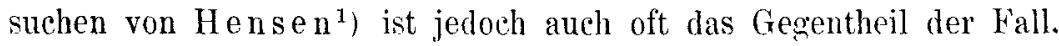
Wir werden daher gut thun, die gewöhnliche Exponentialformel beizubehalten. Uebrigens haben auch $Z$ watromaker und $Q u i x$ im Laufe der Untersuchungen gefunden, dass die gewöhnliche Exponentialformel das Abklingen ihrer Stimmgabeln besser wiedergiht, und haben schliesslich auch ihre letzten Versuchsreihen damit berechnet.

Wenn wir in ihrer Tabelle III (S. 376) diese beiden Correctionen ( $a^{2}$ statt $a^{1.2}, e^{-l t t}$ statt $e^{-l t^{0,9}}$ ) einführen, so erwibt sich die Tabelle XXI. Darin bedeuten $h, 1_{2} a_{t}$, und $V$ die Werthe von

1) Hensen, Hermann's Handbuch der Physiologie S. 120. 
$\mathrm{Zw}$ a arde $\mathrm{m}$ aker und $\mathrm{Qu}$ i ${ }^{1}$ ), nämlich Dämpfungsfactor, Schwellenamplitude, Tonenergie pro Secunde. Die entsprechenden gestrichelten Bezeichnungen geben die umgerechneten Werthe. Die letzte Columne enthält die Empfindlichkeit für lie einzelnen Töne, wenn die für den Ton $32=1$ gesetzt wird.

Tabelle XXI.

Umgerechnete Tabelle von $\mathrm{Z}$ wardemaker und Quix.

\begin{tabular}{|c|c|c|c|c|c|c|c|c|}
\hline & $N$ & $h$ & $h^{\prime}$ & $1 / 2 a t$ & $1 / 2 a t^{\prime}$ & $V$ & $V^{\prime}$ & $E / E_{32}$ \\
\hline $\begin{array}{l}C-1 \\
C \\
G \\
c \\
g \\
c_{1} \\
g_{1} \\
c_{2} \\
g_{2} \\
c_{3}\end{array}$ & $\begin{array}{r}32 \\
64 \\
96 \\
128 \\
192 \\
256 \\
384 \\
512 \\
768 \\
1024\end{array}$ & $\begin{array}{l}0,0457 \\
0,1086 \\
0,0683 \\
0,0519 \\
0,0602 \\
0,0662 \\
0,436 \\
0,2013 \\
0,0801 \\
0,1362\end{array}$ & $\begin{array}{l}0,0338 \\
0,0805 \\
0,0481 \\
0,0350 \\
0,0417 \\
0,0440 \\
0,368 \\
0,154 \\
0,068 \\
0,114\end{array}$ & $\begin{array}{l}1,75 \cdot 10-2 \\
2,5 \cdot 10-3 \\
2,2 \cdot 10-4 \\
2,4 \cdot 10-4 \\
1,05 \cdot 10-4 \\
1,1 \cdot 10-4 \\
5,5 \cdot 10-5 \\
1,9 \cdot 10-5 \\
3,2 \cdot 10-6 \\
2,4 \cdot 10-6\end{array}$ & $\left|\begin{array}{l}1,75 \cdot 10-2 \\
2,5 \cdot 10-3 \\
1,7 \cdot 10-4 \\
1,9 \cdot 10-4 \\
7,5 \cdot 10-5 \\
3,9 \cdot 10-5 \\
2,4 \cdot 10-5 \\
8,5 \cdot 10-6 \\
5,2 \cdot 10-7 \\
3,4 \cdot 10-7\end{array}\right|$ & $\begin{array}{r}6400 \\
1940 \\
190 \\
148 \\
940 \\
257 \\
3750 \\
264 \\
102 \\
175\end{array}$ & $\begin{array}{c}550 \\
37 \\
2,8 \cdot 10-1 \\
2,7 \cdot 10-1 \\
4,6 \cdot 10-1 \\
5,5 \cdot 10-2 \\
3,4 \cdot 10-2 \\
1,97 \cdot 10-8 \\
2,5 \cdot 10-4 \\
2,7 \cdot 10-4\end{array}$ & $\begin{array}{c}1 \\
14,9 \\
1,9 \cdot 103 \\
2,0 \cdot 103 \\
1,2 \cdot 10^{3} \\
1,0 \cdot 104 \\
1,6 \cdot 104 \\
2,8 \cdot 105 \\
2,2 \cdot 10^{6} \\
2,0 \cdot 10^{6}\end{array}$ \\
\hline
\end{tabular}

Der Vergleich von $V$ mit $V^{\prime}$ beweist, wie gross die Wirkung der beiden genannten Fehlerquellen ist. Die letzte Columne zeigt eine Uebereinstimmung der relativen Empfindlichkeit nit meinen Resultaten, wie sie in Anbetracht der sonstigen Unsicherheit der Stimmgabelmethode kaum grösser erwartet werden kann.

$\mathrm{Z}$ wa ardemaker und $\mathrm{Qu}$ ix haben sehr wohl die Unsicherheit erkannt, die in der Berechnung der Schwellenamplitude der Stimmgabeln mit Hülfe der Stefanini'schen Formel liegt. Sie versuchten daher im weiteren Verlauf ihrer Untersuchnng diese zu umgehen, indem sie durch Hörrohre von $0,7 \mathrm{~cm}$ Durchnesser und 60 bezw. $450 \mathrm{~cm}$ Länge den Ton beobachteten. 1)ie Stimmgabel umgaben sie, um die Reflexion an den Zimmerwänden zu vermeiden, mit einer Hohlkugel aus Watte von $15 \mathrm{~cm}$ Radius; in diese mündete unmittelbar an der Oberfläche das Hörrohr. Dadurch gelangte der Ton so geschwächt zum Ohr, dass die Schwellenamplitude der Stimmgabel meist direct beobachtet werden kounte.

1) Ein Theil der Werthe ist gegenüber den im Original angefübrten Zahlen verändert, weil sich dort, wie die Herren Zw wardemaker und Quix mir freundlichst bestätigten, eine Reihe entstellender Druck- bezw. Rechenfehler eingeschlichen hatte. 
Wenn nur etwas Reflexion an der Watte vorhanden ist, so wird in der engen Kugel, deren Radius erheblich kleiner ist als alle untersuchten Wellenlängen, die Schallbewegung eine total andere sein als obne dieselbe. Und auch wenn vollkommene Absorption stattfände, würde die Bewegung im Innern wesentlich von der abweichen, welche beim Uebergang in die freie Luft vor sich geht. Ferner muss bei dem Eintritt in das enge Hörrohr wieder starke Beugung stattfinden, und bei dem engen Lumen $(0,7 \mathrm{~cm})$ werden besonders in dem längeren Rohr die Töne durch Reibung geschwächt. Schliesslich entstehen in dem Hörrohr, wie in einer Kund t'schen Röhre, stehende Schwingungen, die je nach der Wellenlänge sehr stark oder sehr schwach sein können. Es scheint so, als ob diese Resonanzwirkung der stehenden Schwingungen auch in den Versuchsreihen zu Tage tritt, indem in der Tabelle die $c$-Töne meist kleinere Schwellenwerthe aufweisen als die $g$-Töne. Vor Allem hat der Ton $c_{2}(N=512)$ eine Schwellenenergie, die nach der Berechnung von $\mathrm{Zwa}$ watemaker und $\mathrm{Quix} 12 \mathrm{bis} 13 \mathrm{Mal}$, nach der Rechnung mit $a^{2} 90$ Mal schwächer ist als die des nächst tieferen Tones $g_{1}(N=384)$ und 7 bezw. $8 \mathrm{Mal}$ schwächer als die des näehst höheren Tones $g_{2}(N=768)$. In der Schlusstabelle figurirt daher $c_{2}$ als isolirtes Maximum der Empfindlichkeit, das sogar 5 Mal höher liegt als das eigentliche Maximum bei $f_{4}(N=2732)$.

Wegen dieser sehr erhehlichen Fehlerquellen, wozu noch die olsen erörterten allgemeinen der Stimmgabelmethode hinzutreten. glaube ich, dass diesen Versuchen noch weniger Gewicht beizulegen ist wie den vorher besprochenen, die ohne Hörrohr und Wattekugel angestellt wurden.

Für Untersuchungen, wie die vorliegende, ist die Stimmgabel eine viel zu complicirte Tonquelle und die Schwierigkeiten, welche einer genauen Bestimmung der von ihr ausgesandten Tonenergie entgegenstehen, dürften unüberwindliche sein. Es ist sehr zu bedauern, dass aus diesem Grunde die mühevollen und sorgfältigen Stimmgabelversuche von $\mathrm{Zwa}$ ardemaker und $\mathrm{Quix}$ nur sehr wenig zuverlässige Resultate ergeben konnten. 